\title{
Spontaneous high-frequency action potential
}

\author{
SHEN HaiYing \& Wonchae CHOE* \\ Department of Biochemistry and Molecular Biology, Medical Research Center and Biomedical Science Institute, School of Medicine, \\ Kyung Hee University, Seoul 130-701, Republic of Korea
}

Received November 22, 2010; accepted December 27, 2010

\begin{abstract}
Action potential, which is the foundation of physiology and electrophysiology, is most vital in physiological research. This work starts by detecting cardiac electrophysiology (tachyarrhythmias), combined with all spontaneous discharge phenomena in vivo such as wound currents and spontaneous neuropathic pain, elaborates from generation, induction, initiation, to all of the features of spontaneous high-frequency action potential-SSL action potential mechanism, i.e., connecting-end hyperpolarization initiates spontaneous depolarization and action potential in somatic membrane. This work resolves the conundrums of $i n$ vivo spontaneous discharge in tachyarrhythmias, wounds, denervation supersensitivity, neurogenic pain (hyperalgesia and allodynia), epileptic discharge and diabetic pain in pathophysiological and clinical researches that have puzzled people for a hundred years.
\end{abstract}

action potential, spontaneous high-frequency action potential, tachyarrhythmias, atrial fibrillation, wound, denervation supersensitivity, neurogenic pain, hyperalgesia and allodynia, epileptic discharge, diabetic pain, regeneration and development

Citation: Shen H Y, Choe W C. Spontaneous high-frequency action potential. Sci China Life Sci, 2011, 54: 311-335, doi: 10.1007/s11427-011-4157-y

Wound, nerve disconnection, and atrial fibrillation (AF) induced by the excessive atrial dilation, are commonly characterized by the spontaneous repetitive discharge. Their common induction is the disconnection of intercellular connection, and their common result is the initiation of spontaneous high-frequency discharge, which discloses the existence of the special action of intercellular connection.

The Hodgkin-Huxley model has predicted, and the computer models in applied mathematics have well demonstrated, that potassium leakage causes persistent spontaneous electrifying state with spontaneous oscillation of high-frequency action potential. The sustained disconnection of connecting-end space induces potassium leakage in the connecting-end and consequently the sustained reduction of $\left[\mathrm{K}^{+}\right]_{\mathrm{i}}$, which induces in vivo spontaneous high-frequency action potential in plasmalemma.

*Corresponding author (email: wchoe @khu.ac.kr)
To form an intercellular conduction, connecting-end space exerts action on ion diffusions, the alteration of the space alters ion diffusions (i.e., ionic permeability) in the connecting-end. The abolishment of connecting-end space action causes $\mathrm{K}^{+}$leakage and consequently the reduction of intracellular positive electropotential (IPE) (i.e., the increase of intracellular negative potential), which elevates resting somatic membrane potential and initiates action potential in somatic membrane. SSL action potential is named to the course from the initiation (i.e., connecting-end hyperpolarization) to the termination of somatic membrane action potential.

Tachyarrhythmias that are characterized by spontaneous discharge have been most deeply studied. Their inductions contain both mechanical actions and chemical actions, and their courses contain the transformation from traditional action potential to SSL-type action potential, thus tachyarrhythmias meticulously exhibit the characteristic of SSL 
action potential. AF potential, due to its participants of $\mathrm{K}^{+}$, $\mathrm{Cl}^{-}, \mathrm{Na}^{+}$, and $\mathrm{Ca}^{2+}$, acts as the optimal model to comprehend the mechanism of SSL action potential from induction to initiation, amplitude, duration, maintenance, termination, and chaotic property that leads to variable manifestations of SSL-type action potential.

The four highlights of this work are as follows:

(i) It discloses the pathophysiological mechanisms of in vivo spontaneous discharge involving tachyarrhythmias, wound current, denervation supersensitivity, neurogenic pain (hyperalgesia and allodynia), epileptic discharge, and diabetic pain, all of which are the conundrums that have puzzled pathophysiological and clinical researchers for a hundred years.

(ii) The various achievements in methodologies and techniques in physiology, including electrochemistry, applied mathematics and computer modeling, electrophysiological techniques, immunohistochemistry, experimental and clinical mapping, electrocardiography and electromyography, are unified into an organic whole. The aim is not only to recognize the ionic mechanism of spontaneous high-frequency action potential, but also to deeply comprehend the characteristic of SSL action potential mechanism.

(iii) It clarifies the two homeostatic states of the cell, and the two action potential mechanisms derived from them from generation, induction, initiation, to their individual special features and significances in physiology and pathophysiology. It gives deep comprehension on the two homeostatic states of the closed phospholipid membrane and the two action potentials arisen on them.

(iv) It highlights the paramount significance of spontaneous high-frequency action potential in pathophysiology (especially cell regeneration and tissue repair) and embryonic development. Disconnection-potential (i.e., persistent spontaneous high-frequency SSL action potential caused by the disconnection of cell-to-cell connection) is characterized by the longstanding spontaneous repetitive high-frequency discharge and electric field. It creates miraculous and inconceivable "perpetual motion" of bioelectricity to support cell regeneration and tissue repair. It further outlines the perspective of utilizing bioelectric "perpetual motion" for bioenergetic exploitation in the future.

The three foci in this work are emphasized here:

(i) The transformation of cytomembrane polarization state in spontaneous action potential: the hyperpolarized state of the connecting-end and the depolarized state of somatic membrane; somatic membrane depolarization is the consequence of connecting-end hyperpolarization, i.e., the cause-and-effect relationship between the hyperpolarized connecting-end and the depolarized somatic membrane.

(ii) The level of spontaneous somatic membrane depolarization is determined by intracellular/extracellular electropotential.

(iii) The preliminary recognition of the physical and chemical behaviors of connecting-end space, which origi- nate from the establishment of intercellular conduction.

\section{Tachyarrhythmogenesis}

\subsection{Tachyarrhythmogenesis in $\mathrm{Cx} 43$ severe reduction}

Connexins, or gap junction proteins, are a family of structurally-related transmembrane proteins that assemble to form vertebrate gap junctions. Each gap junction is composed of two end-to-end hemichannels. Connexin 43 (Cx43) predominates in virtually all myocytes of the working atrialand ventricular mammalian myocardium [1-4]. The severe reduction of $\mathrm{Cx} 43$ in the connecting-end had been generally regarded as the sign of the occurrence of tachyarrhythmias by immunolabeling in a large number of reports [5-15].

Cx43 is inserted into plasma membrane at the connecting-end of myocardiocytes with the reciprocal joint of two counterpart hemichannels (the connecting-end of myocardiocyte, i.e., the longitudinal end of myocardiocyte, is the end in the longitudinal direction of myocardiocyte which functions as intercellular conduction). Cx43 expression in the longitudinal end is related to the depolarized state of membrane. Catecholamines promoted $\mathrm{Na}^{+}$and $\mathrm{Ca}^{2+}$ inward shift. The connecting-end was remarkably depolarized. Salameh et al. [16,17] reported both catecholamines led to a concentration-dependent increase in $\mathrm{Cx} 43$ protein and mRNA expression. Unopposed connexin hemichannels exhibited robust closure and disappearance in immunolabeling in response to membrane hyperpolarization and extracellular hypercalcemia [18-27]. The severe reduction of Cx43 in the longitudinal end indicated the hyperpolarized state of longitudinal end or extracellular hypercalcemia. Because most of tachyarrhythmia-induced experiments were undergone without the condition of extracellular hypercalcemia, the extracellular hypercalcemia was excluded, thus only membrane hyperpolarization was tenable. As well known, the hyperpolarization of plasmalemma generates from the enhanced $\mathrm{K}^{+}$outflow, concomitant with the inhibited $\mathrm{Na}^{+}$ and $\mathrm{Ca}^{2+}$ inflows (inflow, i.e., inward diffusion; outflow, i.e., outward diffusion).

Hence, the severe reduction of $\mathrm{Cx} 43$ in the longitudinal end (i.e., the connecting-end) signifies the hyperpolarized state of the connecting-end that results from the enhanced $\mathrm{K}^{+}$outflow and the inhibited $\mathrm{Na}^{+}$and $\mathrm{Ca}^{2+}$ inflows in the connecting-end, which induces tachyarrhythmias.

\subsection{Tachyarrhythmogenesis in conduction defect}

End-stage heart failure was characterized by the changes in conduction velocity that predisposed to arrhythmias, reported by Akar et al. [5-7]. In pace-induced heart failure model (the myocardia in pace-induced heart failure are of volume-hypertrophy, i.e., high compliance hypertrophy), two stages were divided by conduction velocity: (i) In the 
early stage, conduction velocity was preserved first and then slightly decreased, concomitant with the gradual reduction of $\mathrm{Cx} 43$ in the longitudinal ends (i.e., the connecting-ends of myocardiocytes); (ii) in the late stage of conduction defect, conduction velocity was significantly decreased, preceded by the severe reduction of $\mathrm{Cx} 43$ in the longitudinal ends, leading to the sustained ventricular tachyarrhythmias.

Myocardial excitation is initiated by $\mathrm{Na}^{+}$inflow. $\mathrm{Na}^{+}$inflow velocity in the longitudinal end determines the conduction velocity between cells; norepinephrine (NE) promotes $\mathrm{Na}^{+}$inflow and accelerates conduction, while acetylcholine (ACh) inhibits $\mathrm{Na}^{+}$inflow and slows conduction. Thus, the slight conduction decline in the early stage indicates $\mathrm{Na}^{+}$inflow is slightly inhibited; the conduction defect in the late stage indicates $\mathrm{Na}^{+}$inflow is severely inhibited in the connecting-end.

As shown earlier, the severe reduction of $\mathrm{Cx} 43$ results from the hyperpolarized state that is induced by the excessive $\mathrm{K}^{+}$outflow and the inhibited $\mathrm{Na}^{+}, \mathrm{Ca}^{2+}$ inflow. Thus, conduction defect concomitant with the severe reduction of $\mathrm{Cx} 43$ in the connecting-end essentially indicates the coexistence of the severely inhibited $\mathrm{Na}^{+}$and $\mathrm{Ca}^{2+}$ inflows and the enhanced $\mathrm{K}^{+}$outflow. Thus, the severely inhibited $\mathrm{Na}^{+}$and $\mathrm{Ca}^{2+}$ inflows and the enhanced $\mathrm{K}^{+}$outflow in the connecting-end induce tachyarrhythmias.

\subsection{Tachyarrhythmogenesis in reentry}

Reentry, i.e., reentrant tachycardia, is characterized by the tachycardia that is triggered by the unidirectional conduction block in the initial depolarization [28,29]. The phenomena of reentry universally exhibit in atrial tachycardia (AT), AF, supraventricular tachycardia (SVT, involving atrioventricular node reentry (AVNRT), atrioventricular reentrant tachycardia (AVRT), Wolff-Parkinson-White syndrome (WPW)) and ventricular tachycardia (VT) [28,29].

"Unidirectional conduction block" well reveals in intracardiac mapping, with the manifestation of a prolonged conduction duration. The "unidirectional conduction block" is essentially the "burst" of conduction defect. As described earlier, the block of conduction results from the severely inhibited $\mathrm{Na}^{+}$and $\mathrm{Ca}^{2+}$ inflows and the enhanced $\mathrm{K}^{+}$outflow in the connecting-end.

Histological biopsies showed the severe reduction of Cx43 in the conducting-edge was generally found responsible for the reentry induction which was elicited by the occurrence of "unidirectional conduction block". For instance, Cx43 was known localized within atrioventricular nodal tissues, reported by Gourdie et al. [30], but as AVNRT attacked, reported by Nikolski et al. [8], immunolabeling revealed that the fast pathway (FP) and slow pathway (SP) were formed by $\mathrm{Cx} 43$-expressing bundles surrounded by tissue without $\mathrm{Cx} 43$. As described earlier, Cx43 disappearance results from the hyperpolarized state with the enhanced $\mathrm{K}^{+}$outflow.
In summary, unidirectional conduction block and its consequently tachyarrhymia-initiation generate from the severely inhibited $\mathrm{Na}^{+}$and $\mathrm{Ca}^{2+}$ inflows concomitant with the enhanced $\mathrm{K}^{+}$outflow in the connecting-end.

\subsection{Tachyarrhythmogenesis in stretch}

Stretch induced extrasystole and tachyarrhythmias, reported by a large number of studies [31-44]. It was explained by mechanoelectric feedback (MEF), and MEF in the heart was in terms of longitudinal cell stretch.

Stretch-sensitive potassium channel contributed to stretch-induced tachyarrhythmias, reported by Kelly et al. [40,41,45,46]. As myocardiocytes were mechanically stretched, an outwardly rectifying $\mathrm{K}^{+}$current component with a conductance of approximately $100-130 \mathrm{pS}$ was detected in whole-cell recordings in rat ventricular myocytes, and underlay the drop in refractoriness. The reduction in plateau and repolarization duration was induced by stretch, reported by Franz et al. [31,33,34,38,39,47]. The shortening of plateau phase results from either of the two factors: the acceleration of $\mathrm{K}^{+}$outflow or the acceleration of $\mathrm{Ca}^{2+}$ inflow. The acceleration of $\mathrm{Ca}^{2+}$ inflow occurs in hypercalcemia, hypokalemia, and the action of NE. These factors all attenuate $\mathrm{K}^{+}$outflow; they can only quicken plateau phase by enhancing $\mathrm{Ca}^{2+}$ inflow, but cannot quicken the whole course of repolarization. By contrast, the enhanced $\mathrm{K}^{+}$outflow quickens both plateau phase and repolarization duration. Therefore, that the stretch induces the reduction in both plateau phase and repolarization duration results from the enhanced $\mathrm{K}^{+}$outflow but not the enhanced $\mathrm{Ca}^{2+}$ inflow. The slowing of conduction and conduction block is also induced by the acute volume-load stretch, which was explained by the inactivation of $\mathrm{Na}^{+}$channels, reported by Kuijpers et al. $[48,49]$. It indicated $\mathrm{Na}^{+}$inflow in the connecting-end was inhibited by stretch. To summarize, the stretch that leads to the attack of arrhythmias causes the enhanced $\mathrm{K}^{+}$ outflow and the inhibited $\mathrm{Na}^{+}$and $\mathrm{Ca}^{2+}$ inflows in the connecting-end.

In the variable volume-load stretch experiments that induced arrhythmias, Franz et al. [33] detailed the region related to foci. An isolated Langendorff-perfused (volume-load) rabbit heart model was developed, the regions of greater myocardial compliance that experienced greater relative stretch contributed to the "foci" for stretch-activated arrhythmias, involving both tachyarrhythmias and blocks.

The high compliance of myocardia, i.e., myocardial dilation, generally results from longitudinally elongated myocardiocytes but not transversely elongated myocardiocytes, because myocardiocytes align as the reticulum configuration. Volume-load hypertrophy has a high compliance. It enlarges the chamber with the increase of the length of myocytes and appears eccentric hypertrophy, and it has a high morbidity of arrhythmias. For instance, longstanding mitral regurgitation with the massive enlarged chamber has 
an almost invariable AF morbidity. By contrast, pressure-load hypertrophy has a low compliance. It narrows the chamber with the increase of the width of myocardiocytes and appears concentric hypertrophy, and it has an even poor morbidity of arrhythmia. For instance, acute mitral regurgitation with a slightly enlarged chamber had few of AF morbidity $[50,51]$. Hence, the high compliance with the remarkable dilation in the longitudinal direction confers the high morbidity of tachyarrhythmias.

In anisotropic stretch experiment of myocardium, reported by Gopalan et al. [52], the principal strain transverse to the axis of cardiac myocytes (10\% transverse stretch combined with 5\% longitudinal stretch) showed an increased immunofluorescent labeling of $\mathrm{Cx} 43$ in the longitudinal end of cardiac myocytes; by contrast, the principal strain parallel to the axis of cardiac myocytes (10\% longitudinal stretch combined with 5\% transverse stretch) had little effect on $\mathrm{Cx} 43$ expression. It was longitudinal stretch but not transverse stretch that suppressed Cx43 expression.

Although the high compliance that sustains the remarkable dilation in the longitudinal direction has the high morbidity of tachyarrhythmias, the attack of tachyarrhythmias shows not directly related to the elongation of myocytes. As described earlier, the early stage of heart failure that has gotten the elongation of myocytes has a poor attack of tachycardias, whereas the late stage of heart failure that has the severe enlarged chamber with the severe reduction of Cx43 expression has a high risk of tachycardias attack. As described earlier, in the pace-induced heart failure model (volume hypertrophy, high compliance hypertrophy), ventricular tachyarrhythmias merely occur in the late stage of conduction defect, in which conduction velocity was significantly decreased, preceded by the severe reduction of Cx43 in the connecting-end. Thus, the elongation of myocardiocytes per se does not induce tachyarrhythmias, but the "additional" elongation in the longitudinal direction, i.e., the dilation of connecting-end space, plays the key role in the severe reduction of $\mathrm{Cx} 43$ expression and the attack of tachyarrhythmias. The length of myocardium in the longitudinal direction of myocytes is comprised of the longitudinal length of myocardiocytes and the space between two counterpart longitudinal ends. The stress of stretch in the longitudinal direction of myocardiocytes elongates the length of myocytes and simultaneously elongates the spacing of connecting-end space. Thus, the "additional" elongation-the dilation of connecting-end space between two counterpart longitudinal ends - shows responsible for the induction of tachyarrhythmias. That the high compliance induces tachyarrhythmias essentially results from the dilation of connecting-end space.

Hence, the "greater compliance" (i.e., high compliance) in the reports signifies the greater dilation of connecting-end space between two counterpart longitudinal ends, which shows highly susceptible to arrhythmias. That stretch induces arrhythmias is by excessively dilating the connect- ing-end space between two counterpart longitudinal ends. As shown earlier, the stretch that leads to the attack of arrhythmias causes the enhanced $\mathrm{K}^{+}$outflow and the inhibited $\mathrm{Na}^{+}$and $\mathrm{Ca}^{2+}$ inflows in the connecting-end, indicating the enhanced $\mathrm{K}^{+}$outflow and the inhibited $\mathrm{Na}^{+}$and $\mathrm{Ca}^{2+}$ inflows in the connecting-end results from the dilation of connecting-end space between two connecting-ends.

In summary, (i) the stretch that induces arrhythmias enhances $\mathrm{K}^{+}$outflow and inhibits $\mathrm{Na}^{+}$and $\mathrm{Ca}^{2+}$ inflows; (ii) that stretch induces arrhythmias is by excessively dilating the connecting-end space between two connecting-ends; (iii) the dilation of connecting-end space causes the enhanced $\mathrm{K}^{+}$ outflow and the inhibited $\mathrm{Na}^{+}$and $\mathrm{Ca}^{2+}$ inflows in the connecting-end to initiate arrhythmias; (iv) high compliance of myocardium signifies the dilation of connecting-end space.

\subsection{Atrial tachyarrhythmogenesis in vagal accentua- tion}

Vagus nerve predominately innervates atria, vagal innervation in atria is much more than sympathetic innervation, and vagal innervation in atria is significantly more than vagal innervation in ventricles.

Vagal stimulation had been used for the induction and maintenance of AF (and supraventricular tachycardias) in experimental protocols for decades, reported in a large number of studies [53-57]. Vagal action releases ACh into the connecting-end space between myocardiocytes. As well known, ACh promotes $\mathrm{K}^{+}$outflow and inhibits $\mathrm{Na}^{+}$and $\mathrm{Ca}^{2+}$ inflows in the connecting-end, by which it causes hyperpolarization of connecting-end membrane meanwhile slows conduction.

The persistent vagal stimulation caused the persistent release and accumulation of ACh [53-57], the concentration of ACh was highly increased in atria, $\mathrm{K}^{+}$outflow was significantly promoted, meanwhile $\mathrm{Na}^{+}$and $\mathrm{Ca}^{2+}$ inflows were severely inhibited. Longitudinal end membrane was remarkably hyperpolarized due to the remarkably enhanced $\mathrm{K}^{+}$outflow and the inhibited $\mathrm{Na}^{+}$and $\mathrm{Ca}^{2+}$ inflows; the accentuation of $\mathrm{K}^{+}$outflow caused the excessive $\mathrm{K}^{+}$leakage, which caused transient hyperkalemia (high $\left[\mathrm{K}^{+}\right]_{\mathrm{o}}$ ) in atria; intercellular conduction was remarkably slowed due to the inhibited $\mathrm{Na}^{+}$inflow, which revealed a prolonged $\mathrm{P}$ wave duration in electrocardiography (ECG). Thus, the excessive release of ACh greatly enhances $\mathrm{K}^{+}$outflow to induce hyperpolarization in the longitudinal end, meanwhile greatly inhibits $\mathrm{Na}^{+}$and $\mathrm{Ca}^{2+}$ inflows in the longitudinal end to induce conduction slowing and conduction block in atria.

ACh infusion reduces $\mathrm{Cx} 43$ expression in atria. In one study, Liu et al. [58] found that Cx43 expression was significantly decreased in the atrial regions that had complex fractionated electrograms. This decreased Cx43 expression potentially contributed to initiate AF, compared with non-complex fractionated electrogram sites. The excessive ACh causes remarkably hyperpolarized connecting-end, and 
as shown earlier, the decreased $\mathrm{Cx} 43$ expression results from membrane hyperpolarization.

In summary, vagal accentuation causes the excessive ACh released into connecting-end space, the excessive ACh causes excessive $\mathrm{K}^{+}$outflow, concomitant with the inhibited $\mathrm{Na}^{+}$and $\mathrm{Ca}^{2+}$ inflows in the connecting-end, leading to the attack of atrial tachyarrhythmias.

Additionally, as well known, atrial compliance is enhanced by vagal stimulation or ACh infusion, in which the excessive $\mathrm{K}^{+}$outflow causes transient hyperkalemia in atria. It leads to a higher volume response to pressure, i.e., the high compliance of atrial myocardium (compliance reflects absolute changes in volume following changes in pressure; compliance $(C)$ presents the slope of the pressure-volume relationship; $C=\Delta V / \Delta P, \Delta V=$ change in volume and $\Delta P=$ change in pressure [59]). As shown earlier, the high compliance of myocardium signifies the dilation of connecting-end space. That the excessive $\mathrm{ACh}$ and consequently high $\left[\mathrm{K}^{+}\right]_{\mathrm{o}}$ causes the high compliance of atrial myocardia indicates that the chemical actions of ACh and high $\left[\mathrm{K}^{+}\right]_{\mathrm{o}}$ dilate connecting-end space.

\subsection{Ventricular tachyarrhythmogenesis and automatic nervous action in acute myocardial ischemia and Bru- gada syndrome}

Acute myocardial ischemia and Brugada syndrome show a high susceptibility of ventricular tachyarrhythmias (VT and VF), both of which are notably characterized by the accelerated $I_{\mathrm{k}}$ and consequently ST segment elevation in monophasic action potential and ECG.

Acute ischemia and hypoxia severely reduce the production of ATP due to the deficiency of oxygen supply. The lack of ATP inhibits sodium-potassium pump (i.e., $\mathrm{Na}^{+}-\mathrm{K}^{+}$ ATPase) in plasmalemma, it causes quantities of $\mathrm{K}^{+}$leakage and consequently local high $\left[\mathrm{K}^{+}\right]_{\mathrm{o}}$ in damaged regions. As well known, high $\left[\mathrm{K}^{+}\right]_{\mathrm{o}}$ promotes $\mathrm{K}^{+}$outflow, thus $\mathrm{K}^{+}$outflow in the non-ischemic cells that locates adjacent to ischemic cells is remarkably enhanced in the connecting-end. It causes hyperpolarization in the connecting-end of the cells adjacent to ischemic myocardiocytes.

Severs [60] detailed in 1994 that confocal laser scanning microscopy of anti-Cx43 immunolabeled samples revealed loss of the usual ordered distribution of gap junctions at border zones adjacent to infarct scars and reduction in the quantity of $\mathrm{Cx} 43$ gap junctions in myocardium distant from the infarct might result in reduced conduction velocity $(\mathrm{CV})$, thereby forming a proarrhythmic substrate. Peters [12] detailed that in myocardium distant from infarction $\mathrm{Cx} 43 \mathrm{had}$ a $47 \%$ reduction in gap junction surface area per unit cell volume. de Diego et al. [61] detailed that during coverslip ischemia, local CV slowed progressively with loss of excitability, CV slowing was accompanied by $\mathrm{Cx} 43$ reduction, action potential duration was shortened, $\mathrm{Ca}$ (i) transient duration was prolonged, and spontaneous reentry occurred in five of 11 monolayers arising from the border zone. CV slowing indicates the inhibited $\mathrm{Na}^{+}$inflow; $\mathrm{Ca}(\mathrm{i})$ transient duration being prolonged indicates the inhibited $\mathrm{Ca}^{2+}$ inflow; the shortened action potential duration and the prolonged $\mathrm{Ca}(\mathrm{i})$ transient duration indicate it is the enhanced $\mathrm{K}^{+}$outflow that causes the shortened action potential duration, but not the enhanced $\mathrm{Ca}^{2+}$ inflow (the enhanced $\mathrm{Ca}^{2+}$ inflow also shortens action potential duration). Zhang et al. $[9,10]$ and Beardslee et al. [11] detailed that in acute myocardial ischemia or hypoxia, Cx43 expression occurred remarkable reduction in the longitudinal end, which was regarded to contribute to the onset of reentrant arrhythmias in acute myocardial ischemia or hypoxia, especially in sudden coronary death whose myocardium had no apparent morphological changes. Hence, the severe ischemia or hypoxia causes the enhanced $\mathrm{K}^{+}$outflow concomitant with the inhibited $\mathrm{Na}^{+}$and $\mathrm{Ca}^{2+}$ inflows to induce ventricular tachyarrhythmias.

Ventricles are predominately innervated by sympathetic nerve. Vagus nerve has a rather poor innervation, which is sharply distinct from vagal innervation in atria. Vagal action affects ventricles mainly by "competitive inhibition" with sympathetic nerve in the center, and vagal action affects ventricles by inhibiting the release of NE.

Sympathetic tone enhances the release of NE, NE enhances myocardial contraction, which increases the consumption of oxygen, thus aggravates the deficiency of ATP production and consequently the deficiency of $\mathrm{Na}^{+}-\mathrm{K}^{+} \mathrm{AT}-$ Pase in plasmalemma. $\mathrm{K}^{+}$leakage is aggravated to initiate ventricular tachyarrhythmias, thus sympathetic tone promotes the induction of ventricular tachyarrhythmias (VT/VF) in acute myocardial ischemia. By contrast, vagal tone inhibits sympathetic tone to reduce myocardial oxygen consumption, by which $\mathrm{K}^{+}$leakage is reduced, thus vagal tone reliefs and inhibits the attack of ventricular tachyarrhythmias in acute myocardial ischemia.

Brugada syndrome is associated with lethal VF. Brugada syndrome has a severely accelerated $I_{\text {to }}$ (transient outward $\mathrm{K}^{+}$current) with the loss of AP dome in the monophasic action potential and consequently a severe ST segment elevation in ECG compared to that in moderate ischemia, $\mathrm{K}^{+}$ outflow is significantly enhanced. Cardiac events of Brugada syndrome typically occurred during sleep or rest [62]. The sleep or rest enhanced vagal tone and inhibited sympathetic tone, which in turn reduced the release of NE that inhibits $\mathrm{K}^{+}$outflow (NE promotes $\mathrm{Na}^{+}$and $\mathrm{Ca}^{2+}$ inflows, and inhibits $\mathrm{K}^{+}$outflow), so $\mathrm{K}^{+}$outflow was further enhanced compared to the state without the inhibition of sympathetic tone, thus vagal tone further enhanced $\mathrm{K}^{+}$outflow in Brugada syndrome. In laboratory, VF was also induced by the additional vagal nerve stimulation in Brugada syndrome model [63]. Ventricular tachyarrhythmias of VT/VF were induced in Brugada syndrome by the application of pinacidil, a potassium channel openers (PCOs) [64]. To summarize, because Brugada syndrome per se has a sig- 
nificantly enhanced $\mathrm{K}^{+}$outflow, vagal tone or potassium channel openers further enhance $\mathrm{K}^{+}$outflow to cause the excessive $\mathrm{K}^{+}$outflow.

$S C N 5 A$-mutation type Brugada syndrome is characterized by the remarkably inhibited $\mathrm{Na}^{+}$inflow in monophasic action potential with the shortened spike potential [62]. Vagal tone inhibits the release of NE, the inhibition of NE further inhibits $\mathrm{Na}^{+}$inflow (NE promotes $\mathrm{Na}^{+}$and $\mathrm{Ca}^{2+}$ inflows, and inhibits $\mathrm{K}^{+}$outflow). Additionally, the sever ischemia or hypoxia may also present the same manifestation as Brugada syndrome in monophasic action potential and ECG with both the accelerated $I_{\text {to }}$ and the inhibited $\mathrm{Na}^{+}$inflow.

Right ventricular outflow tract (RVOT) had been identified as the source of the electrocardiographic abnormalities and arrhythmic activity in patients with Brugada syndrome, reported by Antzelevitch et al. [65,66]. Magnetic resonance imaging in patients with Brugada syndrome showed that the RVOT was selectively dilated, reported by Papavassiliu et al. [67], reflecting RVOT dilation contributed to the development of an arrhythmogenic substrate.

Abnormal expression of cardiac neural crest cells in the heart development was regarded as the etiopathogenesis of Brugada syndrome, reported by Elizari et al. [68]. The studies had shown that conditional knockout of $\mathrm{Cx} 43$ in neural crest cells led to selective dilatation of the outflow tracts in the mouse, reported by Ewart et al. [69]. Germline knockout of $\mathrm{Cx} 43$ in the mouse resulted in swelling and blockage of RVOT, leading to perinatal death, reported by Reaume et al. [70].

In summary, (i) both ischemia-induced VT and Brugada syndrome-induced VF are induced by the enhanced $\mathrm{K}^{+}$outflow, concomitant with the severely inhibited $\mathrm{Na}^{+}$and $\mathrm{Ca}^{2+}$ inflows in the connecting-end; (ii) because the original inductions of ischemia-induced VT and Brugada syndrome are distinct, ischemia-induced VT is intensified by sympathetic tone, because sympathetic tone increases oxygen consumption, which aggravates oxygen deficiency to cause $\mathrm{K}^{+}$leakage and local high $\left[\mathrm{K}^{+}\right]_{\mathrm{o}}$; by contrast, Brugada syndrome that per se has a significantly enhanced $\mathrm{K}^{+}$outflow is intensified by vagal tone, because vagal tone inhibits the release of NE, which in turn promotes $\mathrm{K}^{+}$outflow; (iii) the local high $\left[\mathrm{K}^{+}\right]_{\mathrm{o}}$ caused by the severe ischemia or hypoxia reduces $\mathrm{Cx} 43$ expression.

\subsection{Summary I: Tachyarrhythmias are caused by the enhanced $\mathrm{K}^{+}$outflow and the inhibited $\mathrm{Na}^{+}$and $\mathrm{Ca}^{2+}$ inflows in the connecting-end}

The severe reduction of $\mathrm{Cx} 43$ in the connecting-end, conduction defect in the connecting-end, the stretch that excessively dilates connecting-end space between two counterpart longitudinal ends, the excessive $\mathrm{ACh}$ in the connecting-end space, acute myocardial ischemia and Brugada syndrome induce tachyarrhythmias in myocardiocytes by the enhanced $\mathrm{K}^{+}$outflow concomitant with the inhibited $\mathrm{Na}^{+}$ and $\mathrm{Ca}^{2+}$ inflows in the connecting-end.

The result caused by the enhanced $\mathrm{K}^{+}$outflow concomitant with the inhibited $\mathrm{Na}^{+}$and $\mathrm{Ca}^{2+}$ inflows in the connecting-end involves the following aspects.

(i) Conduction block: Intercellular conduction is blocked and abolished by the severe inhibited $\mathrm{Na}^{+}$inflow in the connecting-end, which causes the disconnection of conduction.

(ii) Hyperpolarized state of the connecting-end: The enhanced $\mathrm{K}^{+}$outflow in the connecting-end results in the hyperpolarized state of the connecting-end; the remarkably hyperpolarized state of the connecting-end causes the severe reduction of $\mathrm{Cx} 43$ in the connecting-end.

(iii) $\mathrm{K}^{+}$leakage and consequently $\left[\mathrm{K}^{+}\right]_{\mathrm{i}}$ reduction: The enhanced $\mathrm{K}^{+}$outflow causes $\mathrm{K}^{+}$leakage and consequently the reduction of intracellular $\mathrm{K}^{+}$concentration.

(iv) IPE reduction: The enhanced $\mathrm{K}^{+}$outflow and the inhibited $\mathrm{Na}^{+}$and $\mathrm{Ca}^{2+}$ inflows cause the reduction of intracellular $\mathrm{K}^{+}, \mathrm{Na}^{+}$, and $\mathrm{Ca}^{2+}$ and consequently the reduction of intracellular positive electropotential (IPE).

To summarize, the enhanced $\mathrm{K}^{+}$outflow concomitant with the inhibited $\mathrm{Na}^{+}$and $\mathrm{Ca}^{2+}$ inflows causes conduction block, connecting-end hyperpolarization, $\mathrm{K}^{+}$leakage, the reduced $\left[\mathrm{K}^{+}\right]_{\mathrm{i}}$, and the reduced IPE. These changes lead to the initiation of tachyarrhythmias.

\subsection{Summary II: The inductions that lead to the en- hanced $\mathrm{K}^{+}$outflow concomitant with the inhibited $\mathrm{Na}^{+}$ and $\mathrm{Ca}^{2+}$ inflows in the connecting-end}

The inductions, which lead to the enhanced $\mathrm{K}^{+}$outflow and the inhibited $\mathrm{Na}^{+}$and $\mathrm{Ca}^{2+}$ inflows in the connecting-end to cause tachyarrhythmias, mainly contain (i) physical action, the mechanical stress of stretch that excessively dilates connecting-end space between two counterpart connecting-ends; and (ii) chemical action, the excessive ACh and high $\left[\mathrm{K}^{+}\right]_{\mathrm{o}}$ in connecting-end space. The physical action in connecting-end space by dilation and the chemical actions in connecting-end space by excessive Ach and high $\left[\mathrm{K}^{+}\right]_{\mathrm{o}}$ have the identical result to initiate tachyarrhymias in myocardium that they both cause the enhanced $\mathrm{K}^{+}$outflow and the inhibited $\mathrm{Na}^{+}$and $\mathrm{Ca}^{2+}$ inflows, and consequently cause the reduced $\left[\mathrm{K}^{+}\right]_{\mathrm{i}}$ and the reduced IPE.

The inductions that lead to the dilation of connecting-end space involve the following aspects.

(i) Mechanical stress (i.e., physical stress): The stretch is caused by mechanical stress, and the dilation caused by stretch is the so-called mechanical dilation.

Due to the hemodynamic function of the heart that uptakes and outputs blood, the in vivo stretch can be caused by hemodynamic dilation and myodynamic dilation. The increase of volume-load causes hemodynamic dilation, especially in atria.

Myodynamic dilation bases on the strong contraction-relaxation motion of myocardiocytes, mainly in ventri- 
cles and especially in left ventricle (LV). The contraction-relaxation motion of myocardiocytes in the dyssynchronous motion stretches adjacent myocardiocytes or muscle bundle. For instance, the dyssynchronous motion occurs between normal myocardiocytes and the damaged cells of ischemia, infarct or scar, or occurs in left bundle branch block. David et al. [71] reported that LV discoordination and mechanical dyssynchronous contraction were studied by magnetic resonance 3D tagged images. Marked downregulation of $\mathrm{Cx} 43$ expression $(60 \%$ reduction relative to other segments) was observed, and underlay enhanced arrhythmia susceptibility. By contrast, similar expression was not seen in LV coordination preserved model, indicating the importance of dyssynchrony to arrhythmia susceptibility. Spragg et al. [72] reported that dyssynchronously contracting LV underwent left bundle branch radiofrequency ablation, produced heterogeneous regional wall stress and worsened arrhythmia susceptibility. It was likely to generate a potent arrhythmogenic substrate, and Cx43 absence in the longitudinal end was notably seen, whereas changes in myocardiocyte length, width or myocardial fibrosis were not seen.

(ii) Chemical action (i.e., chemical stress): The chemical actions of $\mathrm{ACh}$ and high $\left[\mathrm{K}^{+}\right]_{\mathrm{o}}$ cause the enhanced $\mathrm{K}^{+}$outflow and the inhibited $\mathrm{Na}^{+}$and $\mathrm{Ca}^{2+}$ inflows in the connecting-end. Meanwhile, the excessive $\mathrm{ACh}$ and high $\left[\mathrm{K}^{+}\right]_{\mathrm{o}}$ dilate connecting-end space lead to the high compliance of myocardium. This dilation of connecting-end space is caused by chemical stress, which is the so-called chemical dilation.

(iii) De-junctions: The loss or disturbance of intercalated discs causes the de-joining between cells. It causes dilation and disconnection of connecting-end space. Zemljic et al. [73-76] reported that the loss of intercalated discs induced dilated cardiomyopathy and lethal arrhythmias; Severs et al. [77,78] reported that the disturbance of intercalated discs at the border zone of healed infarcts was the region that appeared susceptibility of tachyarrhythmias.

To summarize, physical dilation, chemical dilation, and de-junctions all can induce the dilation and consequently the disconnection of connecting-end space. The excessive dilation and disconnection of connecting-end space cause the excessively enhanced $\mathrm{K}^{+}$outflow and the severely inhibited $\mathrm{Na}^{+}$and $\mathrm{Ca}^{2+}$ inflows in the connecting-end, which results in conduction block, connecting-end hyperpolarization, $\mathrm{K}^{+}$ leakage, and the excessively reduced IPE. These changes initiate the attack of tachyarrhythmias.

\subsection{Summary III: Mechanochemical action and chemomechanical action in connecting-end space}

The dilation of connecting-end space causes the enhanced $\mathrm{K}^{+}$outflow concomitant with the inhibited $\mathrm{Na}^{+}$and $\mathrm{Ca}^{2+}$ inflows, thus the alteration of connecting-end space alters ion diffusions and consequently ion distributions, by which the mechanical stress induces the alteration of ion diffusions and consequently intracellular/extracellular ion distributions.

ACh accentuation and high $\left[\mathrm{K}^{+}\right]_{\mathrm{o}}$ dilate connecting-end space in atria. By contrast, the opposite action (ACh attenuation and low $\left[\mathrm{K}^{+}\right]_{\mathrm{o}}$ ) corrects the dilation and restores the normal connecting-end space, which indicates that ACh and $\left[\mathrm{K}^{+}\right]_{\mathrm{o}}$ alter the connecting-end space by their chemical properties.

Mechanochemistry (i.e., the space influences ion diffusions) and chemomechanics (i.e., the chemicals influence the space) in connecting-end space exhibit the speciality of connecting-end space, in which the space and the chemicals can interact. Thus, the connecting-end space is not the space in the general sense, but has the special attribute that both physical action (e.g., stretch) and chemical action (e.g., ACh) can influence it to influence ion diffusions and consequently intracellular/extracellular ion distributions.

1.10 Total summary: Tachyarrhythmogenesis highlights two novae-spontaneous action potential and connecting-end space

The mechanism on tachyarrhythmogenesis highlights two novae: (i) spontaneous action potential and (ii) connectingend space.

Tachyarrhymias are the spontaneous action potentials that spontaneously (i.e., endogenously) arise in myocardiocytes. As shown earlier, conduction defect that has the severe reduction of $\mathrm{Cx} 43$ in the longitudinal end induces tachyarrhymias, and conduction defect fails to conduct excitation and initiate action potential in cells, thus tachyarrhythmias are of spontaneous action potentials.

Tachyarrhymias are initiated by connecting-end hyperpolarization, which is caused by the enhanced $\mathrm{K}^{+}$outflow and the inhibited $\mathrm{Na}^{+}$and $\mathrm{Ca}^{2+}$ inflows, and consequently the reduced IPE. These mechanisms cause the attack of spontaneous action potential in myocardiocytes.

The connecting-end space is not the space in the general sense, but has the special attribute that both physical action (e.g., stretch) and chemical action (e.g., ACh) can influence it to influence ion diffusions and consequently intracelluar/ extracellular ion distributions. Both physical action and chemical action can induce $\mathrm{K}^{+}$leakage from the connecting-end. The excessive dilation and disconnection of connecting-end space induce excessive $\mathrm{K}^{+}$leakage from the connecting-end to initiate spontaneous action potential.

\section{Distinct polarization states between connect- ing-end and somatic membrane}

\subsection{Tachyarrhythmias and $\mathrm{Cx} 43$ redistribution from connecting-end to lateralized somatic membrane}

Histological biopsies of tachyarrhythmiac tissues all com- 
monly exhibited a vital characteristic of myocardiocytes whose $\mathrm{Cx} 43$ was in lateralized location concomitant with Cx43 overexpression [5,12,79-82]. Peters [12] detailed in the report "New insights into myocardial arrhythmogenesis" in 1996 that at the myocardial interface with the scar of a healed infarct, $\mathrm{Cx} 43$ gap junction distribution was grossly disturbed, being strewn in longitudinally orientated arrays along the lateral interfaces between degenerated but viable myocytes, which might be due to a redistribution of the pre-existing population of junctions. This altered distribution was present as early as four days after coronary occlusion in a canine model, in which it defined the location of circuits causing ventricular tachycardias. Akar et al. [5,79] detailed that $\mathrm{Cx} 43$ redistribution from the intercalated disk to lateral cell borders was a late event that coincided with marked reduction of conduction velocity to predispose to tachyarrhythmias. Nygren et al. [80] detailed that $\mathrm{Cx} 43$ showed a significant redistribution, apparent as enhanced Cx43 lateralization. It was quantified and found to be significantly larger than in control myocytes, and it contributed to arrhythmogenesis. Peters et al. [81] detailed that a marked disruption of gap-junctional distribution, with $\mathrm{Cx} 43$ labeling abnormally arrayed longitudinally along the lateral surfaces of the cells, was the determinant of VT susceptibility by defining the location of the common central pathway of the reentrant VT circuits. Polontchouk et al. [82] reported that immunohistologic analysis indicated that AF resulted in an increase in the immunostaining of $\mathrm{Cx} 43$ at the lateral membrane of human atrial cells, and a similar spatial redistribution of the $\mathrm{Cx} 43$ signal was seen in isolated rat atria with experimentally-induced AF.

In review, distinct from the connecting-end (i.e., longitudinal end) distribution in normal, $\mathrm{Cx} 43$ redistribution in tachyarrhythmogenesis is characterized by the lateralization (i.e., longitudinally distributed along the lateral surface) with a high density (also termed "overexpression" or "superexpression"). The connecting-end membrane locates in the longitudinal end of myocardiocyte; the non-connecting-end membrane, i.e., somatic membrane, locates in the lateral surface of myocardiocyte. The "redistribution" of Cx43 from the longitudinal end (i.e., connecting-end) to lateral surface (i.e., somatic membrane) with a high density indicates that the states of connecting-end membrane and non-connecting-end membrane in tachyarrhythmias are sharply distinct from their states in normal.

Generally, connexins opened as the reciprocal approach, i.e., typic-channels, in the connecting-ends and form the junctions with the counterpart. Under the condition of membrane depolarization or extracellular hypocalcemia (low $\left[\mathrm{Ca}^{2+}\right]_{\mathrm{o}}$ ), connexins opened without the approach of counterparts and form hemi-channels [17-27]. Because extracellular hypocalcemia is excluded in tachyarrhythmia-induced experiments, Cx43 redistribution in non-connecting-end membrane with hemi-channels without the counterpart-joints signifies that $\mathrm{Cx} 43$ hemi-channel lateralization results from the depolarized state of somatic membrane. By contrast, the absence of $\mathrm{Cx} 43$ in connecting-end membrane signifies that connecting-end membrane is landed into the highly hyperpolarized state. It indicates the states of connecting-end (hyperpolarized) and somatic membrane (depolarized) in tachyarrhythmic myocardiocytes are distinct from the states of connecting-end (depolarized) and somatic membrane (hyperpolarized) in the normal state.

The density of $\mathrm{Cx} 43$ expression is closely related to the depolarized state of membrane. Catecholamines promote cation inward shift, involving the resting phase, which promotes the depolarization of the connecting-end. Salameh et al. $[16,17]$ reported that both catecholamines led to a concentration-dependent increase in $\mathrm{Cx} 43$ protein and mRNA expression. Thus, Cx43 overexpression with the high density in lateralization signifies the highly depolarized state of somatic membrane.

In summary, the "redistribution" of $\mathrm{Cx} 43$ from connecting-end to somatic membrane with a high density signifies (i) the highly hyperpolarized state of the connecting-end, and as a consequence action potential is unable to arise in the connecting-end; and (ii) the highly depolarized state of somatic membrane, and as a consequence action potential is able to be spontaneously elicited by the highly depolarization in somatic membrane. Hence, the spontaneous action potential of tachyarrhythmias arises in somatic membrane but not the connecting-end. It is in the state that connecting-end membrane is highly hyperpolarized and somatic membrane is highly depolarized.

As tachyarrhythmias occur, the connecting-end membrane has been transformed from depolarized state into highly hyperpolarized state, the non-connecting-end membrane (i.e., somatic membrane) has been transformed from hyperpolarized state into highly depolarized state, and the highly depolarization of somatic membrane consequently initiates action potential in somatic membrane.

Also, the action potential mechanism of a cell is not absolutely static, but can be changed by the polarization state of the connecting-end: The depolarized state of the connecting-end leads to traditional action potential; the highly hyperpolarized state of the connecting-end leads to spontaneous action potential.

\subsection{Distinct cytomembranes between connecting-end and somatic membrane}

The distinct polarization states between connecting-end and somatic membrane (i.e., non-connecting-end membrane) in the normal state and the disconnection state reveal that the cytomembranes of connecting-end and somatic membrane are distinct.

In the normal state, $\mathrm{Cx} 43$ distributes only in the connecting-end but not in the somatic membrane. The connecting-end membrane is basically landed into depolarized state whereas the somatic membrane is in hyperpolarized state. It 
signifies the cations in connecting-end space are basically inwardly "driven", i.e., inwardly rectified, by the normal connecting-end space state. $\mathrm{Na}^{+}$inflow is basically furthered whereas $\mathrm{K}^{+}$outflow is basically restrained to cause the depolarization of the connecting-end. As a consequence, the disconnection of connecting-end space abolishes the inwardly rectifying action, $\mathrm{Na}^{+}$inflow is inhibited whereas $\mathrm{K}^{+}$outflow is enhanced to cause the hyperpolarization of the connecting-end.

In pathologic state, the dilation and disconnection of connecting-end space cause the inhibited $\mathrm{Na}^{+}$and $\mathrm{Ca}^{2+}$ inflows and the enhanced $\mathrm{K}^{+}$outflow. It in turn indicates that the normal connecting-end space state fundamentally exerts an inwardly rectifying action on cation diffusions.

Hence, both the depolarized state of connecting-end in the normal connecting-end space state and the hyperpolarized state of connecting-end in the disconnection state signify that the normal connecting-end space fundamentally exerts an inwardly rectifying action to ion diffusions.

To form the conduction between two connecting-ends, two counterparts of connecting-ends are joined to set up connecting-end space, which basically exerts the inwardly "driving" force to cations, i.e., inwardly rectifying action on cations. The direction of the driving force (i.e., rectifying action) exerted to cations is consistent with the direction of $\mathrm{Na}^{+}$and $\mathrm{Ca}^{2+}$ inward diffusions, which propels $\mathrm{Na}^{+}$and $\mathrm{Ca}^{2+}$ inflows, but is opposite to the direction of $\mathrm{K}^{+}$outward diffusion, which resists $\mathrm{K}^{+}$outflow.

In summary, despite both belong to the cytomembrane, the inwardly rectifying action exerted by the normal state of connecting-end space results in the distinct ionic permeability between connecting-end and somatic membrane. This distinction generates from the evolutionary adaptability that connecting-end space should benefit forming the conduction from one cell to the other so that the excitation can be propagated by ion diffusions. The normal connecting-end space basically functions exerting an inwardly rectifying action to cation diffusions. This function derives two results: (i) The dilation and disconnection of the connecting-end cause the reduction of IPE; (ii) the alteration of the space alters ion diffusions and consequently intracellular/extracellular ion distributions.

\subsection{The identity of electric field lateralization induced by disconnection: Lateralized electric field in wounds}

Wound-induced electric field had been studied since it was first demonstrated in wounds by Emil DuBois-Reymond (the father of experimental electrophysiology) [83] 150 years ago. "All the electric phenomena which it manifests being due to internal molecular changes associated with activity or injury" (in his work Researches on Animal Electricity, from 1848 to 1884). Micro-electric current had been detected in wounds in both epithelial and non-epithelial tissues in human and other mammals using various modern techniques [84-92]. Sta et al. [84] and Nuccitelli et al. [85] reported the endogenous lateral electric fields around corneal and other epithelial lesions. Song et al. [86] detailed the features: "In cornea and skin, a laterally oriented, wound-induced d.c. (direct current) electric field is generated instantaneously when the epithelium is damaged, and it persists until re-epithelialization restores the electrical resistance barrier function of the epithelium". These electric fields were estimated to be $40-50 \mathrm{mV} \mathrm{mm}{ }^{-1}$ at cornea wounds and $100-150 \mathrm{mV} \mathrm{mm}^{-1}$ at skin wounds [84-86,91,92]. They arose because of spatial and temporal variations in epithelial transport of charged ions such as $\mathrm{Na}^{+}, \mathrm{K}^{+}$and $\mathrm{Cl}^{-}$, and spatial variations in the electrical resistance of epithelial sheets [86].

The essence of wounds is the destroy exerted to cells and consequently the influence that the destroyed cells exert to the adjacent non-injured cells connected to them-the loss of connecting-end connection and the disconnection of conduction. The disconnection of connecting-end space "instantaneously" generates endogenous and laterally oriented electric field covering the somatic membrane with high-frequency and rapid propagation. The "d.c. electric field" indicates the attack and propagation of action potentials (direct current electric field is formed by the running-on of continuous action potentials along membrane surface (depolarization $-\rightarrow$ repolarization + )) [86,92]. The "endogenous" indicates the action potentials are spontaneously arisen by the cell per se, but not elicited by exogenous conduction. The "laterally oriented" indicates the action potentials originate in somatic membrane but not connecting-end membrane. It "persists until re-epithelialization" indicates (i) the spontaneous action potential is generated by the connecting-end disconnection, and the persistent spontaneous high-frequency action potentials are generated by the sustained connecting-end disconnection; (ii) the restoration of connecting-end space terminates the spontaneous action potential. Thus, the endogenous and laterally oriented electric field in wound is essentially the spontaneous action potential firing in somatic membrane, which is generated by the loss of connection (i.e., the disconnection) between cells caused by the wound.

Wound electric field and tachyarrhymias are both characterized by spontaneously electrifying, and they are both generated by the connecting-end disconnection. It indicates that the mechanisms of spontaneous electrifying in wound and tachyarrhythmias are identical that the connecting-end disconnection induces the spontaneous high-frequency action potential in somatic membrane.

\subsection{Summary}

The cell underlying spontaneous electrifying is characterized by connecting-end hyperpolarization, somatic membrane depolarization and consequently spontaneous action potential in somatic membrane. The distribution of sponta- 
neous action potential is characterized by high density, lateralized, long distance, and rapid propagation over somatic membrane.

\section{Ionic mechanism of spontaneous high-fre- quency action potential}

\subsection{Prediction of Hodgkin-Huxley model}

It had been predicted in Hodgkin-Huxley model (1963 Nobel Prize in Physiology or Medicine) [93] that the certain persistent spontaneous electrifying state, or being called a stable electric leakage state, would induce infinite continuous impulses in excitable cells such as neurons and cardiac cells. It was demonstrated in applied mathematics and computer modeling, reported by Aihara et al. [94] and Kager et al. [95], that the potassium leakage or increasing extracellular potassium concentration caused the spontaneous oscillation with high-frequency action potential.

As well known, the direction of ion diffusion is determined by the ionic concentration gradient. The ions in the compartment of high concentration permeate to the counterpart of low concentration according to electrochemical potential gradient. $\mathrm{K}^{+}$concentration in intracellular fluid is remarkably higher than that in interstitial fluid; this electrochemical gradient drives the flow of $\mathrm{K}^{+}$and forms the trend of $\mathrm{K}^{+}$outward diffusion. Thus, the enhanced $\mathrm{K}^{+}$outward diffusion that causes $\mathrm{K}^{+}$leakage can induce electric leakage state.

According to Nernst equation $\left(\mathrm{Ek}=\mathrm{RT} / \mathrm{ZF} \ln \left[\mathrm{K}^{+}\right]_{\mathrm{o}} /\left[\mathrm{K}^{+}\right]_{\mathrm{i}}\right.$ ), either the increased $\left[\mathrm{K}^{+}\right]_{\mathrm{o}}\left(\left[\mathrm{K}^{+}\right]_{\mathrm{o}} \uparrow\right)$ or the reduced $\left[\mathrm{K}^{+}\right]_{\mathrm{i}}$ $\left(\left[\mathrm{K}^{+}\right]_{\mathrm{i}} \downarrow\right)$ elevates $\mathrm{K}^{+}$equilibrium potential and resting membrane potential to initiate the spontaneous depolarization of somatic membrane. In laboratory, potassium leakage model was commonly set up by the significantly high $\left[\mathrm{K}^{+}\right]_{\mathrm{o}}$ milieu. It was because high $\left[\mathrm{K}^{+}\right]_{\mathrm{o}}$ shortens $\left[\mathrm{K}^{+}\right]_{\mathrm{i} \text {-o }}$ gradient $\left(\left[\mathrm{K}^{+}\right]_{\mathrm{o}} \uparrow \rightarrow\left[\mathrm{K}^{+}\right]_{\mathrm{o}} /\left[\mathrm{K}^{+}\right]_{\mathrm{i}} \uparrow\right)$, which elevated resting potential to cause the spontaneous depolarization of somatic membrane. Distinct from the significantly high $\left[\mathrm{K}^{+}\right]_{\mathrm{o}}$ in laboratory, the in vivo spontaneous action potential arises without the significantly high $\left[\mathrm{K}^{+}\right]_{\mathrm{o}}$ as that of in vitro experiments. Thus only $\left[\mathrm{K}^{+}\right]_{\mathrm{i}} \downarrow$, i.e., $\mathrm{K}^{+}$leakage, concomitant with high $\left[\mathrm{K}^{+}\right]_{\mathrm{o}}$ or not, can cause the in vivo spontaneous action potential. The dilation and disconnection of connecting-end space cause the enhanced $\mathrm{K}^{+}$outflow that $\mathrm{K}^{+}$outflow is accentuated compared to a normal one, which causes $\mathrm{K}^{+}$ leakage from the connecting-end and the reduced $\left[\mathrm{K}^{+}\right]_{\mathrm{i}}$, thus the result of in vivo "potassium leakage" is primarily set up by $\mathrm{K}^{+}$leakage from the connecting-end and consequently the reduced $\left[\mathrm{K}^{+}\right]_{\mathrm{i}}\left(\left[\mathrm{K}^{+}\right]_{\mathrm{i}} \downarrow\right)$. The reduced $\left[\mathrm{K}^{+}\right]_{\mathrm{i}}$ shortens $\left[\mathrm{K}^{+}\right]_{\mathrm{i} \text { oo }}$ gradient $\left(\left[\mathrm{K}^{+}\right]_{\mathrm{i}} \downarrow \rightarrow\left[\mathrm{K}^{+}\right]_{\mathrm{o}} /\left[\mathrm{K}^{+}\right]_{\mathrm{i}} \uparrow\right)$, and the resting somatic membrane potential is spontaneously elevated and depolarized to initiate action potential. The sustained dis- connection of connecting-end space causes the sustained state of $\mathrm{K}^{+}$leakage and the reduced $\left[\mathrm{K}^{+}\right]_{\mathrm{i}}$. It initiates spontaneous high-frequency action potential in vivo and maintains for a long period (e.g., permanent-AF or wound electric field).

In conclusion, that the dilation and disconnection of connecting-end space cause the enhanced $\mathrm{K}^{+}$outward diffusion from the connecting-end and consequently the reduced $\left[\mathrm{K}^{+}\right]_{\mathrm{i}}$, concomitant with high $\left[\mathrm{K}^{+}\right]_{\mathrm{o}}$ or not, is the critical causation of in vivo spontaneous high-frequency action potential in plasmalemma.

In accordance with Nernst equation and Goldman-Hodgkin-Katz equation, the membrane potential depends on the ionic concentration gradients across the membrane, the reduced intracellular cation concentrations and the increased intracellular anion concentrations, i.e., the reduced IPE and the increased intracellular negative electropotential, both elevate the resting membrane potential. The dilation and disconnection of connecting-end space cause the enhanced $\mathrm{K}^{+}$outflow and meanwhile the inhibited $\mathrm{Na}^{+}$and $\mathrm{Ca}^{2+}$ inflows in the connecting-end; the enhanced $\mathrm{K}^{+}$outflow and the inhibited $\mathrm{Na}^{+}$and $\mathrm{Ca}^{2+}$ inflows all reduced intracellular cation concentrations and IPE, which causes the spontaneous depolarization and consequently action potential in plasmalemma.

How to achieve a stable potassium leakage or a stable electricity leakage? If exerted a resisting electric field (also called electrical resistance barrier) to a constant current, enhancing the electric field would weaken the current; oppositely, weakening the electric field would enhance the current and cause the leakage of electricity.

Connecting-end space basically exerts an inwardly rectifying action on cations. The dilation or disconnection of connecting-end space weakens or abolishes the inwardly rectifying action, $\mathrm{K}^{+}$outflow is enhanced, which causes $\mathrm{K}^{+}$ leakage and consequently the reduced $\left[\mathrm{K}^{+}\right]_{\mathrm{i}}$, meanwhile $\mathrm{Na}^{+}$ and $\mathrm{Ca}^{2+}$ inflows are inhibited. The enhanced $\mathrm{K}^{+}$outflow concomitant with the inhibited $\mathrm{Na}^{+}$and $\mathrm{Ca}^{2+}$ inflows causes the hyperpolarization of connecting-end and the reduction of IPE. The sustained state of the dilation or disconnection of connecting-end space results in the sustained hyperpolarized state of the connecting-end and the sustained reduction of IPE, leading to the stable state of potassium leakage and cations leakage (i.e., positive electropotential leakage) of the cell.

\subsection{Spontaneous action potential mechanism in atrial fibrillation potential}

Atrial fibrillation potential, due to the participants of $\mathrm{K}^{+}, \mathrm{Cl}^{-}$, $\mathrm{Na}^{+}$, and $\mathrm{Ca}^{2+}$, contributes to the optimal model to detect the mechanism of spontaneous action potential from induction to initiation, amplitude, duration, maintenance, and termination. Also, chaotic property is detected. 


\subsubsection{Induction}

The excessive dilation and consequently the disconnection of connecting-end space induce tachyarrhythmias. It has been universally acknowledged that a chronic and remarkably large left atrium ( $>4.5 \mathrm{~cm}$ by echocardiography) responds to permanent AF (permanent-AF); AF ultimately develops to permanent-AF which finally stands in atria and permanently keeps in the most sever exacerbation of atrial dilation. Therefore, the excessive dilation and the disconnection of connecting-end space induce AF.

\subsubsection{Initiation}

The excessive dilation and disconnection of connecting-end space cause the enhanced $\mathrm{K}^{+}$outflow concomitant with the inhibited $\mathrm{Na}^{+}$and $\mathrm{Ca}^{2+}$ inflows. It causes the excessive $\mathrm{K}^{+}$ leakage from the connecting-end and the remarkable hyperpolarization of connecting-end membrane, and consequently the reduced $\left[\mathrm{K}^{+}\right]_{\mathrm{i}}$ and the reduced IPE.

$\mathrm{K}^{+}$leakage from the connecting-end remarkably reduces $\left[\mathrm{K}^{+}\right]_{\mathrm{i}}$. According to Nernst equation, the reduced $\left[\mathrm{K}^{+}\right]_{\mathrm{i}}$ shortens $\left[\mathrm{K}^{+}\right]_{\mathrm{i}-\mathrm{o}}$ gradient, the ratio of $\left[\mathrm{K}^{+}\right]_{\mathrm{o}} /\left[\mathrm{K}^{+}\right]_{\mathrm{i}}$ is increased $\left(\left[\mathrm{K}^{+}\right]_{\mathrm{o}} /\left[\mathrm{K}^{+}\right]_{\mathrm{i}} \uparrow\right)$, and $\mathrm{K}^{+}$equilibrium potential and resting membrane potential are elevated in somatic membrane, which causes spontaneous depolarization in somatic membrane. As spontaneous depolarization runs beyond the threshold potential, $\mathrm{Na}^{+}$channel is activated to initiate spontaneous action potential in somatic membrane.

The above course of spontaneous depolarization had been demonstrated in a number of experiments on stretchinduced arrhythmias. Franz et al. [31,33,34,38,39,42] reported that stretch shortened plateau phase and action potential duration, which caused the accelerated $I_{\mathrm{k}}$ and consequently $\mathrm{K}^{+}$leakage. Franz et al. [33] reported that membrane depolarization was caused by both gradual and rapid ventricular stretch, and subsequently extrasystoles were elicited. Riemer et al. [34] reported that the increase of stretch led to the depolarization of resting potential, a decreased excitation threshold and an increased cellular excitability, making the heart prone to ectopic activity. Janse et al. [38] reported that stretch during diastole easily led to depolarization, which might reach the threshold and initiate a premature ventricular beat. Stacy et al. [42] detailed that depolarizations that coincided with the onset of stretch were observed that always preceded the stretch-induced arrhythmia. As stretch volume increased from 10 to $30 \mathrm{~mL}$, the amplitude of the stretch-induced depolarization increased progressively and the probability of eliciting an arrhythmia rose from $30 \%$ to $94 \%$; when the stretch-activated channel blocker $\mathrm{Gd}^{3+}\left(10 \mathrm{mmol} \mathrm{L}{ }^{-1}\right)$ was administered, which produced potent inhibition of stretch-induced arrhythmias in their model, the stretch-induced depolarizations were substantially reduced in magnitude.

Nevertheless, in all the above experiments, a contradiction that had not been resolved was, the enhanced $\mathrm{K}^{+}$outflow should cause the hyperpolarization of membrane; however, the elevation of resting potential and the depolarization occur at the same time of hyperpolarization. As shown earlier, the dilation of connecting-end space enhances $\mathrm{K}^{+}$outflow from the connecting-end, and the enhanced $\mathrm{K}^{+}$outflow from the connecting-end causes the hyperpolarization of the connecting-end; meanwhile the enhanced $\mathrm{K}^{+}$outflow reduces $\left[\mathrm{K}^{+}\right]_{\mathrm{i}}$, the reduced $\left[\mathrm{K}^{+}\right]_{\mathrm{i}}$ causes spontaneous depolarization and action potential in nonconnecting-end membrane (i.e., somatic membrane)-by which the two opposing states of membrane, hyperpolarized state and depolarized state, simultaneously occur in the cell. The distinct cytomembranes between connecting-end and non-connecting-end membrane contribute to the coexistence of the hyperpolarized connecting-end and the depolarized somatic membrane in a single cell.

The traditional action potential, which is initiated because cation inflows directly depolarize membrane, is the so-called "DD action potential" (directly depolarized action potential). The in vivo spontaneous action potential, which is initiated because cation leakage in connecting-end causes the reduced IPE to cause spontaneous depolarization and consequently action potential in lateralized somatic membrane, is the so-called SSL action potential (connecting-end space-induced spontaneous lateralized action potential).

\subsection{3 $\mathrm{Cl}^{-}$inflow in the course of connecting-end hyperpo- larization}

$\mathrm{Cl}^{-}$transmembrane gradient $\left(\left[\mathrm{Cl}^{-}\right]_{\mathrm{o}}:\left[\mathrm{Cl}^{-}\right]_{\mathrm{i}}=104: 30\right)$ forms the trend of $\mathrm{Cl}^{-}$inward diffusion. As well known, $\mathrm{Cl}^{-}$channel is activated by the hyperpolarization of membrane, hyperpolarization is elicited by the enhanced $\mathrm{K}^{+}$outflow, and $\mathrm{Cl}^{-}$inflow is secondary to the enhanced $\mathrm{K}^{+}$outflow. The dilation and disconnection of the connecting-end space causes the enhanced $\mathrm{K}^{+}$outflow and consequently hyperpolarization in connecting-end membrane. The hyperpolarization of membrane activates $\mathrm{Cl}^{-}$channel, and extracellular $\mathrm{Cl}^{-}$flows into the cell subsequent to $\mathrm{K}^{+}$outflow, which results in the reduced $\left[\mathrm{K}^{+}\right]_{\mathrm{i}}$ and secondarily the increased $\left[\mathrm{Cl}^{-}\right]_{\mathrm{i}}$.

As the connecting-end space is in the normal state, the $\mathrm{Cl}^{-}$channel $\left(\mathrm{Cl}^{-}\right.$inflow) is inactivated by the depolarized state of the connecting-end. However, as the connecting-end space is in the dilated and disconnected states, $\mathrm{Cl}^{-}$channel is activated by the hyperpolarized state of the connecting-end.

Connecting-end space primarily exerts inwardly rectifying action on cations. In accordance with the principle of electrostatic field, it should meanwhile exert an inversely directed rectifying action (i.e., outwardly rectifying action) on anions (e.g., $\mathrm{Cl}^{-}$). This outwardly rectifying action on anions inhibits anion inflows (mainly $\mathrm{Cl}^{-}$inflow) in the normal state; and as the disconnection that causes hyperpolarized connecting-end occurs, the inhibition exerted to anion inflow is abolished so that anion inflow is enhanced. It 
is identical with the actual result that $\mathrm{Cl}^{-}$inflow is inhibited in the depolarized state of the connecting-end but is enhanced in the hyperpolarized state of the connecting-end.

\subsubsection{Action potential amplitude is influenced by $\left[\mathrm{K}^{+}\right]_{i}$ and $\left[\mathrm{Cl}^{-}\right]_{i}$}

According to Nernst equation and Goldman-HodgkinKatz equation, the reduced $\left[\mathrm{K}^{+}\right]_{\mathrm{i}}$ and the increased $\left[\mathrm{Cl}^{-}\right]_{\mathrm{i}}$ both lessen IPE (intracellular negative electropotential $\uparrow$ ), the absolute value of equilibrium potential is lessened, the resting potential formed by $\mathrm{K}^{+}$equilibrium potential is elevated, and the spike potential formed by $\mathrm{Na}^{+}$equilibrium potential is lowered. Action potential amplitude is the span between the starting point (i.e., resting potential) and the terminal point (i.e., spike potential), the action potential amplitude is remarkably shortened by both resting potential $\uparrow$ and spike potential $\downarrow$, which acts as a rather shortened action potential amplitude in fibrillation action potential.

$\left[\mathrm{K}^{+}\right]_{\mathrm{i}}$ influences spike potential and action potential amplitude. It was shown in the experiments of the excessive vagal stimulation or Brugada-type ST segment elevation added by ACh, both of which had the remarkably accelerated $I_{\mathrm{k}}$ and consequently the remarkably reduced $\left[\mathrm{K}^{+}\right]_{\mathrm{i}}$. In these experiments, reported by Nishida et al. [63] and Yan et al. [64], spike potential and action potential amplitude were remarkably shortened; by contrast, isoproterenol weakened $I_{\mathrm{k}}$ and restored $\left[\mathrm{K}^{+}\right]_{\mathrm{i}}$, which restored spike potential and action potential amplitude. In these experiments, VF was induced by adding vagal stimulation [63] or potassium channel opener pinacidil [64], because they both further promoted $I_{\mathrm{k}}$ and reduced $\left[\mathrm{K}^{+}\right]_{\mathrm{i}}$.

$\mathrm{Cl}^{-}$inflow reduces IPE, and the reduced IPE shortens equilibrium potential, action potential amplitude and action potential duration (detailed later). That $\mathrm{Cl}^{-}$inflow influenced action potential amplitude was well shown in congenital myotonia (also called Thomsen disease). Congenital myotonia resulted from the inherited $\mathrm{Cl}^{-}$channel mutation $\left(\mathrm{Cl}^{-}\right.$inflow is inhibited), and it was characterized by the huge action potential in electromyogram due to the lack of the participant of $\mathrm{Cl}^{-}$.

To summarize, the more reduced IPE causes the more reduced absolute value of equilibrium potential and consequently the more shortened action potential amplitude.

\subsubsection{Action potential duration and frequency}

According to Goldman-Hodgkin-Katz equation [96], the reduced IPE lessens the absolute value of equilibrium potential. $\mathrm{Ca}^{2+}$ equilibrium potential is lowered, by which the termination of $\mathrm{Ca}^{2+}$ inflow is in advance so that the plateau phase is shortened. The termination of $\mathrm{K}^{+}$repolarization is advanced so that repolarization duration is shortened. The reduced $\left[\mathrm{K}^{+}\right]_{\mathrm{i}}$ caused by the enhanced $\mathrm{K}^{+}$outflow and the increased $\left[\mathrm{Cl}^{-}\right]_{\mathrm{i}}$ caused by the enhanced $\mathrm{Cl}^{-}$inflow both cause the reduced IPE which lowers $\mathrm{Ca}^{2+}$ equilibrium po- tential, and the plateau phase, refractory period and action potential duration are shortened. For instance, ACh promotes $\mathrm{K}^{+}$outflow and shortens action potential duration; $I_{\mathrm{Cl}(\mathrm{cAMP})}\left(\mathrm{CFTR}, \mathrm{Cl}^{-}\right.$channel) channel opening also shortens action potential duration.

Therefore, plateau phase, repolarization duration, and consequently action potential duration of spontaneous action potential are remarkably shortened compared to that of normal action potential (i.e., DD action potential), by which the action potential duration of AF is greatly shortened even less than absolute refractory period; also, the cycles of other cardiac tachyarrhythmias are shortened less than refractory period and even less than absolute refractory period of DD action potential.

The remarkably shortened action potential duration results in the high frequency of spontaneous action potential arisen in somatic membrane, which forms the high frequency of AF.

\subsubsection{Maintenance and termination}

The sustained dilation and disconnection of connecting-end space cause the sustained state of $\mathrm{K}^{+}$leakage. Connecting-end membrane is landed into the sustained hyperpolarized state, the intracellular state of the reduced $\left[\mathrm{K}^{+}\right]_{\mathrm{i}}$, the increased $\left[\mathrm{Cl}^{-}\right]_{\mathrm{i}}$, and consequently the reduced IPE persists. The sustained state of the reduced IPE lands somatic membrane into the sustained depolarized state, which makes the action potential (depolarization $\rightarrow$ repolarization) keep standing in somatic membrane, causing spontaneous high-frequency action potential, i.e., fibrillation action potential, firing in somatic membrane of myocardiocyte.

As the dilation and disconnection of connecting-end space are corrected (e.g., atrial dilation is corrected, or vagal accentuation is corrected), the restoration of the normal connecting-end space terminates $\mathrm{K}^{+}$leakage, the hyperpolarized state of the connecting-end is terminated, intracellular electropotential and intracellular/extracellular ion distributions restore to the normal state, the initiation condition of spontaneous depolarization in somatic membrane is abolished, and spontaneous action potential is thus terminated.

\subsubsection{Butterfly effect and chaotic property}

Since Hodgkin-Huxley model was described in 1952 [93], the chaotic property of spontaneous high-frequency action potential in excitable cells had been regarded as a vital characteristic of fibrillation action potential and kept on being studied in non-linear system by the intensive research [94,95,97-99], the chaotic property exhibited system instability with the unstable action potential amplitude and duration. The Hodgkin-Huxley model per se is a set of nonlinear ordinary differential equations that approximate the electrical characteristics of excitable cells such as neurons and cardiac myocytes (non-linear system refers to the system whose variations of results are non-consistent). It gives 
mathematical insight into the dynamics of action potential generation.

Chaos is characterized by the behavior of a certain dynamical system that is highly sensitive to initial conditions [100]. The tiny differences in the starting state of the system can lead to the enormous differences in the final state of the system, thus an arbitrarily small perturbation of the current trajectory may lead to a significantly different future behavior. This sensitivity is popularly referred to the butterfly effect and non-linear expression that a small variation of the initial condition of a dynamical system may produce large variations in the final behavior of the system.

On the other hand, although the initial perturbation is amplified, the chaotic system is constrained all along in the attractor with the bounded system, the motor locus of effect is unable to leave the closed loop attractor (according to the attractor theory of chaotic deterministic system founded by Henri Poincare), and the attractor is equal to the oscillator.

The pathway of chaotic behaviors in SSL action potentials is as follows: SSL action potential is initiated by intracellular/extracellular electropotential, intracellular/extracellular electropotential (involving cations and anions) determines equilibrium potential to determine resting potential, spike potential, and the amplitude, duration and frequency of action potential, consequently determines the entire figure of action potential arisen in somatic membrane. Thus the action potential arisen in somatic membrane is highly sensitive to the initial change of IPE, and a small difference of IPE is amplified to a large difference in the figure of action potential involving amplitude, duration and frequency. It reflects the behaviors (butterfly effect and non-linear expression) of the chaotic system.

SSL action potential is initiated by $\mathrm{K}^{+}$leakage from the connecting-end, and $\mathrm{Cl}^{-}$inflow is secondary to $\mathrm{K}^{+}$leakage. $\mathrm{K}^{+}$leakage and $\mathrm{Cl}^{-}$inflow reduce IPE (intracellular negative electropotential $\uparrow$ ), which greatly shortens the amplitude, duration and frequency of action potential. The levels of $\mathrm{K}^{+}$ leakage and $\mathrm{Cl}^{-}$inflow, and consequently $\left[\mathrm{K}^{+}\right]_{\mathrm{i}}$ and $\left[\mathrm{Cl}^{-}\right]_{\mathrm{i}}$, are influenced by the dilation of connecting-end space, and also influenced by vagal tone (release ACh) and sympathetic tone (release NE). A small variation of connecting-end space or $\mathrm{ACh} / \mathrm{NE}$ release causes the corresponding variation of $\left[\mathrm{K}^{+}\right]_{\mathrm{i}}$ and $\left[\mathrm{Cl}^{-}\right]_{\mathrm{i}}$, which results in the large variations in the amplitude, duration and frequency of AF potential and consequently an significant instability of AF action potentials.

Butterfly effect and non-linear expression were well exhibited in the following cases: The enhanced $I_{\mathrm{k}}$ caused by the excessive vagal stimulation or Brugada-type ST segment elevation added by $\mathrm{ACh}$ resulted in the remarkably shortened action potential amplitude [63,64]; the inhibited $\mathrm{Cl}^{-}$inflow caused by $\mathrm{Cl}^{-}$channel mutation of congenital myotonia resulted in a huge action potential.

Due to the initiation mechanism of SSL action potential that the depolarization of somatic membrane is initiated by the reduction of IPE, the viable values of $\mathrm{K}^{+}$equilibrium potential are permitted in a wide interval, from the threshold potential $\left(\mathrm{Na}^{+}\right.$channel activated potential) to $\mathrm{Na}^{+}$channel inactivated potential or even $\mathrm{Ca}^{2+}$ channel inactivated potential in myocardiocytes. Therefore, the variation of IPE in the large interval leads to the large variations in SSL action potential figure involving amplitude, duration and frequency.

As described earlier, although the initial perturbation is amplified, the chaotic system is constrained all along in the attractor with the bounded system. The depolarization potential caused by the reduced IPE is constrained in the interval from $\mathrm{Na}^{+}$channel activation to $\mathrm{Na}^{+}$channel inactivation, by which the figures of action potential are correspondingly constrained in an interval. It also reflects the behavior (constricted by the attractor) of the chaotic system.

To recap, the chaotic behaviors of SSL action potential result from the initiation mechanism of SSL action potential that the depolarization of somatic membrane is initiated by the reduced IPE or, in other words, by the ratio of intracellular/extracellular electropotential formed by intracellular/extracellular ion distributions: (i) It leads to the pathway that a small difference of IPE or intracellular/extracellular ion distributions, is amplified into a large difference of action potential figure involving amplitude, duration, and frequency, by which the response of the system is highly sensitive and accurate to the initial condition; (ii) it permits large variations of initial condition; (iii) the depolarization potential of somatic membrane is constrained by $\mathrm{Na}^{+}$channel activity. Hence, SSL action potential has the property of the chaotic system, and chaotic behaviors (butterfly effect, non-linear expression, and attractor) are the vital characteristics of SSL action potential.

Besides the chaotic behaviors in tachyarrhythmias, "observations of chaotic behavior also include the dynamics of the action potentials in neurons" and skeletal muscle cells [100]. The chaotic property of SSL action potential responds to the variable initial conditions (ion distributions) with the high sensitivity and accuracy in the plasmalemma of the target cell (e.g., myocardiocyte, neuron, skeletal muscle cell), and also in the closed phospholipid membranes of endomembrane system, which permits large variable manifestations of SSL action potential. The chaotic property of SSL action potential enables the closed phospholipid membrane system to respond to the variable initial conditions (ion distributions) with the variable action potential manifestations.

\subsubsection{Summary}

The course of SSL action potential from initiation, amplitude and duration (frequency), maintenance and termination, to chaotic property, results from the initiation mechanism of SSL action potential that somatic membrane depolarization and action potential are initiated by the reduced IPE or, in other words, by the ratio of intracellular/extracellular elec- 
tropotential.

\section{Connecting-end disconnection and sponta- neous high-frequency action potential in wound current, denervation supersensitivity, and neu- rogenic pain}

\subsection{Wound current}

The essence of wounds is the destroy exerted to cells and consequently the influence that the destroyed cells exert to the adjacent non-injured cells connected to them-the loss of connecting-end connection and the disconnection of conduction, the valid connecting-end space is abolished and causes the disconnection of conduction, and the disconnection of the connecting-end causes endogenous and laterally oriented electric field, as detailed earlier in the section "Lateralized electric field in wounds".

\subsection{Denervation supersensitivity}

In surgical denervation, as well known, the results between de-preganglionic neuron (D-pre) and de-postganglionic neuron (D-post) are completely distinct: De-preganglionic neuron terminates the excessive response of the effector (a target (non-neuron) cell); however, de-postganglionic neuron induces supersensitivity.

When D-pre and D-post are compared, their generality is that they both block the release of transmitters in neuroeffector junction, and the excitation conduction from the neurons to the effectors is completely blocked; their distinction is whether postganglionic neurons that connect with the effectors are destroyed or not. The postganglionic neurons connect with the effectors by presynaptic membranes in the normal state. In D-pre, postganglionic neuron and presynaptic membrane remain without damage; in D-post, postganglionic neuron is severely destroyed and causes degeneration or necrosis. These destroys make neuron lose its primary morphology (shrinking and deforming) and its components (such as gap junctions, adherents, or desmosomes). Consequently, the function of presynaptic membrane that joins with postsynaptic membrane in neuroeffector junction is destroyed, and the connecting-end space of neuroeffector junction between postganglionic neuron and the effector is dilated and disconnected. Therefore, the essential distinction that D-pre and D-post exert to the effectors is the state of presynaptic membrane and consequently the influence exerted to postsynaptic membrane (i.e., the connecting-end of the effector) in neuroeffector junction. In D-pre, the normal presynaptic membrane in postganglionic neuron forms the normal connection which restrains $\mathrm{K}^{+}$outflow from postsynaptic membrane. By contrast, in D-post, the damaged presynaptic membrane in the damaged postganglionic neuron is deformed. It causes the sustained state of $\mathrm{K}^{+}$leakage from postsynaptic membrane which is the connecting-end of the effectors, the sustained state of $\mathrm{K}^{+}$leakage and IPE reduction causes the persistent spontaneous high-frequency SSL action potential that spontaneously arises and maintains in the somatic membrane of the effectors.

A large number of early studies reported that the spontaneous discharges were caused by the various denervations [101-111]. These spontaneous discharges that manifested fibrillation potentials were also termed "denervation potentials" in some reports. The spontaneous and rhythmical repetitive discharges were originated in skeletal muscles due to the denervation process [101-105], and the spontaneous firing activity of muscle fiber that manifested fibrillation potentials was regarded as the safe criteria for the clinical diagnosis of denervation. The spontaneous depolarizing excitations of striatal neurons were observed after the denervation caused by 6-hydroxydopamine-induced lesions of the nigrostriatal dopaminergic system [106-111]. They were related to the nigral cell loss, and the denervation caused the appearance of spontaneous discharge which persisted even after eight months.

The deformation of presynaptic membrane in pathology can be induced by various factors, such as dystrophy, atrophy, degeneration, or necrosis. These factors destroy the morphology, component, and function of presynaptic membrane, and initiate spontaneous high-frequency SSL action potential in the effectors. For instance, the severe compression of median nerve in carpal tunnel syndrome induces neural degeneration and subsequently conduction block. It is associated with fibrillation potentials in the appropriate muscles; neural atrophy induced by lower motor neuron lesions reveals fasciculation and correspondingly fibrillation potentials in electromyograms. Distinct from that acute deletion of the connecting-end immediately induces spontaneous discharge, the occurrence of connecting-end space dilation and disconnection and consequently the attack of spontaneous discharge in the chronic dilation between connecting-ends caused by the chronic course of dystrophy, atrophy or degeneration (e.g., the compression in carpal tunnel syndrome) requires a much longer term compared with that of acute injuries.

To summarize, the essence of denervation supersensitivity is that the deformation of presynaptic membrane causes the dilation and disconnection of neuroeffector junction, and initiates persistent spontaneous high-frequency SSL action potentials firing in the effectors.

\subsection{Neurogenic pain}

Neurogenic pain is characterized by the spontaneous repetitive ectopic discharge in the absence of any external signal stimulation. Neurogenic pains are induced by the block, compression, disconnection, or other impairments in sensory afferent pathways in pathological or experimental conditions. These inductions, in essential, are the variable 
manifestations which destroy the normal connecting-end space in sensory afferent pathway (e.g., dorsal root ganglion). They initiate spontaneous repetitive discharges. The spontaneous repetitive discharges are further conducted into the center to elicit spontaneous pains. Borgens et al. [112-115] reported that the spinal cord responded to the damages of hemisection, transection, and other complete injuries, by generating large and persistent electrical signals.

The partial disconnection in sensory afferent pathway causes hyperalgesia and allodynia. This partial disconnection causes a partial sum of neurons disconnected but not the total of neurons as that in the complete disconnection of nerve. It initiates persistent spontaneous discharge and elicits the limited excitation (i.e., local excitation, local response) in the central neurons, which enhances the sensitivity (i.e., excitability) of the central neurons. Because the central neurons are connected by the divergence and polymerism of synapses, the excitation caused by the partial disconnection may only initiate local excitation that fails to achieve threshold stimuli. As the slight peripheral stimuli (below the pain threshold) attack, the local excitations caused by the peripheral stimuli and the local excitations caused by the partial disconnection are integrated (i.e., summed) in the center, the integrated excitation exceeds pain threshold and forms the supersensitivity of pain with allodynia and hyperalgesia.

\subsection{The definition of disconnection-potential}

The excessive dilation of the connecting-end space between two connecting-ends, or the deformation or absence of the counterpart connecting-end, causes the disconnection between two cells. It was the so-called disconnection, or the disconnection of connecting-end space.

The sustained state of disconnection causes the persistent spontaneous high-frequency SSL action potential. The persistent spontaneous high-frequency SSL action potential caused by disconnection is the so-called disconnectionpotential.

\section{Spontaneous high-frequency action potential in high $\left[\mathrm{K}^{+}\right]_{\mathrm{o}}$}

\subsection{Myocardial hyperkalemia}

According to Nernst equation and Goldman-Hodgkin-Katz equation, the increase of $\left[\mathrm{K}^{+}\right]_{\text {o }}$ elevated resting potential, which was regarded as the single pathway through which in vivo hyperkalemia initiated spontaneous action potential.

In myocardium, high $\left[\mathrm{K}^{+}\right]_{\mathrm{o}}$ in the connecting-end space promotes $\mathrm{K}^{+}$outflow and inhibits $\mathrm{Na}^{+}$and $\mathrm{Ca}^{2+}$ inflows, and the higher $\left[\mathrm{K}^{+}\right]_{\mathrm{o}}$ causes the more enhanced $\mathrm{K}^{+}$outflow and the more inhibited $\mathrm{Na}^{+}$and $\mathrm{Ca}^{2+}$ inflows. Therefore, hyperkalemia causes the accelerated $I_{\mathrm{k}}$ which is characterized by the remarkably elevated ST segment in surface ECG $\left(\mathrm{K}^{+}\right.$ outflow is enhanced), meanwhile intercellular conduction is inhibited $\left(\mathrm{Na}^{+}\right.$inflow is inhibited), and myocardial contractility is attenuated $\left(\mathrm{Ca}^{2+}\right.$ inflow is inhibited). The enhanced $\mathrm{K}^{+}$outflow causes hyperpolarization in the connecting-end and consequently the reduced $\left[\mathrm{K}^{+}\right]_{\mathrm{i}}$. According to Nernst equation, the reduced $\left[\mathrm{K}^{+}\right]_{\mathrm{i}}$ and the increased $\left[\mathrm{K}^{+}\right]_{\mathrm{o}}$ (high $\left[\mathrm{K}^{+}\right]_{\mathrm{o}}$ ) both elevate resting potential. Accordingly, on the basis that high $\left[\mathrm{K}^{+}\right]_{\mathrm{o}}$ preliminarily elevates resting somatic membrane potential, the reduced $\left[\mathrm{K}^{+}\right]_{\mathrm{i}}$ caused by the enhanced $\mathrm{K}^{+}$outflow secondarily elevates resting somatic membrane potential, which subsequently elicits spontaneous action potential in somatic membrane. The higher $\left[\mathrm{K}^{+}\right]_{\mathrm{o}}$ causes the higher preliminary elevation of resting somatic membrane potential by the increased $\left[\mathrm{K}^{+}\right]_{\mathrm{o}}$, meanwhile causes the higher secondary elevation of resting somatic membrane potential by the reduced $\left[\mathrm{K}^{+}\right]_{\mathrm{i}}$. Thus, hyperkalemia is highly susceptible to SSL action potential in myocardium (i.e., tachyarrhythmias), and the higher $\left[\mathrm{K}^{+}\right]_{\mathrm{o}}$ has the higher susceptibility. To summarize, the tachyarrhythmias induced by hyperkalemia are essentially SSL action potentials.

\subsection{Myocardial ischemia or hypoxia}

Ischemia and hypoxia cause the deficient oxygen supply, which reduces ATP production and inhibits sodium-potassium ATPase. The inhibition of sodium-potassium ATPase causes $\mathrm{K}^{+}$leakage. $\mathrm{K}^{+}$leakage accumulates in extracellular fluid because ischemia and hypoxia attack in a range of myocardiocytes, meanwhile microcirculation is inhibited due to ischemia and hypoxia, thus ischemia and hypoxia induce a local high $\left[\mathrm{K}^{+}\right]_{0}$.

The local high $\left[\mathrm{K}^{+}\right]_{\mathrm{o}}$ enhances $\mathrm{K}^{+}$outflow in the connecting-end of non-ischemic myocardiocytes adjacent to ischemic region, which causes the hyperpolarized connecting-end (shown earlier in the section "Ventricular tachyarrhythmogenesis and automatic nervous action in acute myocardial ischemia and Brugada syndrome"). The accelerated $I_{\mathrm{k}}$ is characterized by ST segment elevation in ECG. ST segment elevated, or even transformed into monophasic curve, is the remarkable sign of acute myocardial infarction in myocardial injury phase. The enhanced $\mathrm{K}^{+}$outflow in the connecting-end reduces $\left[\mathrm{K}^{+}\right]_{\mathrm{i}}$ to elevate resting somatic membrane potential, which causes spontaneous depolarization and action potential in somatic membrane. Thus ischemia and hypoxia predispose myocardium to SSL action potential (i.e., tachyarrhythmias).

The severe ischemia and hypoxia cause the severe $\mathrm{K}^{+}$ leakage and consequently the higher $\left[\mathrm{K}^{+}\right]_{\mathrm{o}}$ and the severely reduced $\left[\mathrm{K}^{+}\right]_{\mathrm{i}}$. The resting potential of somatic membrane is so elevated (i.e., depolarized) that approaches the inactivated potential of $\mathrm{Na}^{+}$channel. The inactivated $\mathrm{Na}^{+}$channel causes the non-polarization of somatic membrane (nonpolarization refers to the inactivation of $\mathrm{Na}^{+}$channel caused 
by the excessive depolarization, in which $\mathrm{Na}^{+}$fails to flow into the cell). The non-polarization of myocardiocytes causes pathological Q wave in ECG. Pathological Q wave is the remarkable sign of acute myocardial infarction in myocardial infarction phase, resulting from the absence of electrical activity caused by the excessive depolarization.

\subsection{Epileptic discharge}

Epileptic potential, a pattern of spontaneous high-frequency discharge, is first regarded in relation to the congenital or acquired glial scars. Glial scarring is regarded prone to disturb extracellular substance excretion, and $\mathrm{K}^{+}$fails to output as normal but accumulates in interstitial fluid with a local high $\left[\mathrm{K}^{+}\right]_{\mathrm{o}}$. The early experiments showed a remarkably depolarized potential (beyond $+30 \mathrm{mV}$ ) in the soma of neuron was observed, anticipating the bursts of epileptic potential. Therefore, epileptic potential is essentially spontaneous high-frequency SSL action potential that is initiated by spontaneous somatic membrane depolarization.

Besides glial scarring, the insufficiencies of cerebrovascular blood supply induced by cerebrovascular anomaly, intracranial tumor compression, or other cerebral injuries, induce ischemia and hypoxia that cause $\mathrm{K}^{+}$leakage and consequently a local high $\left[\mathrm{K}^{+}\right]_{\mathrm{o}}$. They initiate spontaneous discharges with spontaneous high-frequency SSL action potential, which also manifest epileptic discharge. Additionally, the dysbolismus in brain may induce the accumulation of $\mathrm{H}^{+}$and $\mathrm{K}^{+}$to initiate spontaneous high-frequency SSL action potential that manifests epileptic discharge.

\subsection{Diabetic pain}

Diabetic peripheral neuropathy is the term for the neuropathy of sensory nerves, motor nerves, or autonomic nerves in diabetes mellitus (DM). It had been confirmed that the attack of diabetic peripheral neuropathy synchronized with the attack of vasopathy, where the blood flow declined in endoneurium, and the vasopathy of DM was characterized by the constriction or even obstruction of microcirculation. The decline of blood flow causes ischemia and hypoxia of tissue, and the microcirculatory ischemia causes $\mathrm{K}^{+}$leakage and $\mathrm{K}^{+}$accumulation to induce local high $\left[\mathrm{K}^{+}\right]_{\mathrm{o}}$. The local high $\left[\mathrm{K}^{+}\right]_{0}$ initiates spontaneous SSL action potential in neurons, and the spontaneous excitation of sensory neurons induces spontaneous pain, hyperalgesia and allodynia (detailed earlier in "Neurogenic pain") in DM.

Microcirculatory constriction can be treated by sympathetic nerve block or disconnection. The release of NE is terminated, and ACh dominates so that vasodilatation replaces vasoconstriction. Microcirculatory ischemia and hypoxia are corrected, which restores blood flow in endoneurium, and the induction of spontaneous action potential is inhibited and terminated. The pain is thus relieved and terminated. By contrast, NE injection induces vasocon- striction and ischemia, which induces spontaneous pain.

Daube [116] detailed in Electrodiagnosis in Clinical Neurology that "Diabetes is the most common cause of a peripheral neuropathy. In diabetes, small vascular lesions in a multifocal distribution result in a variety of patterns of abnormality on nerve conduction studies". "Often, the focal mononeuropathies are superimposed on mild, diffuse change, with generalized reduction in amplitudes of the evoked responses and the mild slowing of conduction." "Some patients with diabetes have a lumbosacral polyradiculopathy manifested primarily by diffuse fibrillation potentials in the L2 to L4 paraspinal muscles."

In conclusion, diabetic pain results from vasopathy that induces ischemia and hypoxia in endoneurium to initiate spontaneous high-frequency SSL action potential in sensory neurons to induce spontaneous pain.

\subsection{Summary}

High $\left[\mathrm{K}^{+}\right]_{\mathrm{o}}$ can be caused by hyperkalemia, or the local high

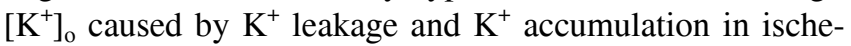
mia and hypoxia, or dysbolismus. High $\left[\mathrm{K}^{+}\right]_{\mathrm{o}}$ in connecting-end space enhances $\mathrm{K}^{+}$outflow. It causes $\mathrm{K}^{+}$leakage and connecting-end hyperpolarization, and the reduced $\left[\mathrm{K}^{+}\right]_{\mathrm{i}}$ further elevates resting somatic membrane potential on the basis that the increased $\left[\mathrm{K}^{+}\right]_{\mathrm{o}}$ elevates resting somatic membrane potential; the higher $\left[\mathrm{K}^{+}\right]_{\mathrm{o}}$ causes the higher elevation of resting potential. Thus high $\left[\mathrm{K}^{+}\right]_{\mathrm{o}}$ has a high susceptibility to induce SSL action potential. In summary, the in vivo spontaneous repetitive discharge in high $\left[\mathrm{K}^{+}\right]_{\mathrm{o}}$ is essentially spontaneous high-frequency SSL action potential.

\section{Pathophysiological and biological significance of spontaneous electric field}

The spontaneous electric field is essentially the spontaneous high-frequency SSL action potential. The persistent spontaneous high-frequency SSL action potential generates the persistent spontaneous discharge so that myocardiocytes, neurons, skeletal muscle cells, and other cells themselves could be the sources of electricity.

Song et al. [86,92,117-122] reported that endogenous electric fields had been measured during regeneration after damage to non-epithelial tissues and during development in vertebrate embryos. Hotary et al. [119,121,123] reported that the disruption of endogenous electrical gradients during development induced skeletal and neural abnormalities. Borgens et al. [112-115] reported that the spinal cord responded to damage by generating large and persistent electrical signals, and in turn applied electric stimulation promoted spinal cord repair in human and other mammals. Hinkle et al. [86,92,124-133] reported that many vitro experiments showed that the electric fields were equivalent to those measured in vivo control important cell behaviors 
such as directional cell migration (galvanotaxis or electrotaxis), cell division orientation, and cell cycle control.

To summarize, spontaneous electric field is requisite for (i) regeneration after damage, (ii) development in vertebrate embryos, and (iii) controlling important cell behaviors.

Additionally, as the injury causes the disconnection between connecting-ends, intercellular conduction is abolished and the downstream conduction is blocked, cellular excitation and cellular function that depend on conduction are also abolished, which leads to dysfunction and atrophy of the cell. Under this condition, disconnection-potentials, i.e., persistent spontaneous high-frequency SSL action potentials caused by the disconnection, are generated to elicit cellular excitation and function, and subsequently elicit conduction and excitation for the downstream cells beneath the injury site. Although the excitation initiated by SSL action potential shows aberrant to the normal state, compared with that conduction block causes the complete loss of excitation, disconnection-potential makes excitation standing in the cell, which effectively avoids and postpones dysfunction and atrophy of the cell, thus the mechanism of SSL action potential definitely plays the role in self-protection and self-compensation.

More importantly, as shown earlier, the persistent spontaneous high-frequency discharge produces persistent endogenous electric field, which has the special functions of (i) recruiting cytokines by the galvanotaxis or electrotaxis of cytokine for anti-infection and anti-inflammation, (ii) recruiting cells (involving somatic stem cells) by the galvanotaxis or electrotaxis of cell migration for the repair of tissue, and (iii) stimulating and activating cytokines and somatic stem cells by the high-frequency electric field signal. Thus, the mechanism of SSL action potential plays the paramount role in wound healing, especially, plays the role in in vivo activating somatic stem cells.

SSL action potential mechanism generates the persistent spontaneous high-frequency action potential, which creates the excitation-standing state of cells or organelles (ER and mitochondria). It offers the "infinite" electric power to support excitation and biochemical reaction of cells and organelles (e.g., the persistent high-frequency SSL action potential of ER contributes to spontaneous $\mathrm{Ca}^{2+}$ oscillation).

\section{Electrodiagnosis of fibrillation potential in neuropathic states}

Electrodiagnosis in Clinical Neurology was edited by Professor Aminoff (Department of Neurology School of Medicine University of California, San Francisco, USA) [134]. The part entitled "Clinical Electromyography" detailed the electromyography activities of fibrillation potential in pathologic states [135]:

"Fibrillation potentials are action potentials that arise spontaneously from single muscle fibers. When they occur rhythmically, their genesis may relate to oscillations of the resting membrane potential of denervated skeletal muscle fibers [136,137]. Less commonly, they occur irregularly; this has been attributed to the occurrence of random, discrete, spontaneous depolarizations that originate in the transverse tubular system of the muscle fiber [138]". "Fibrillation potentials usually have an amplitude of between 20 and $300 \mu \mathrm{V}$, a duration of less than $5 \mathrm{~ms}$, and a firing rate of between 2 and $20 \mathrm{~Hz}$. They have a bi- or triphasic shape, the first phase being positive except when the potentials are recorded in the endplate region. This positive onset facilitates their distinction from endplate noise. Over the loudspearker, they give rise to a high-pitched repetitive click, which aids their detection. They are found in denervated muscle, provided that some tissue remains viable and the muscle is warm when examined; however, they may not appear for 3 to 5 weeks after an acute neuropathic lesion. Once present, they may persist for months or even years, until the muscle fibers have come to be reinnervated or have degenerated, but there is some evidence that their amplitude declines with time [139]. They are not in themselves diagnostic of denervation, however, because they are also seen in primary muscle diseases such as polymyositis, inclusion body myositis, and muscular dystrophy, and in patients with botulism, trichinosis, muscle trauma, or metabolic disorders such as acid maltase deficiency or hyperkalemic periodic paralysis. The presence of fibrillation potentials in myopathic disorders probably relates to isolation of part of the muscle fibers from their endplates, so that they are functionally denervated [140,141]".

The above elaboration on fibrillation potential indicates:

(i) Spontaneous action potential. "Fibrillation potentials are action potentials that arise spontaneously from single muscle fibers".

(ii) Spontaneous depolarization of resting somatic membrane potential. "...their genesis may relate to oscillations of the resting membranes potential of denervated skeletal muscle fibers", "this has been attributed to the occurrence of random, discrete, spontaneous depolarizations that originate in the transverse tubular system of the muscle fiber".

(iii) Somatic membrane depolarization. "...this has been attributed to the occurrence of random, discrete, spontaneous depolarizations that originate in the transverse tubular system of the muscle fiber (in skeletal muscle cell, endplate (i.e., postsynaptic membrane of neuromuscular junction) is the connecting-end, transverse tubular system (i.e., the deep invaginations of the sarcolemma) is of somatic membrane)". "...the first phase being positive (i.e., depolarization) except when the potentials are recorded in the endplate region. This positive onset facilitates their distinction from endplate noise".

(iv) Connecting-end (i.e., endplate) hyperpolarization (negative potential). “...the first phase being positive except when the potentials are recorded in the endplate region. This positive onset facilitates their distinction from endplate 
noise".

(v) Distinct polarization states between connecting-end (hyperpolarized) and somatic membrane (depolarized). "...the first phase being positive except when the potentials are recorded in the endplate region. This positive onset facilitates their distinction from endplate noise".

(vi) The shortened amplitude and duration of action potential. "Fibrillation potential usually have an amplitude of between 20 and $300 \mu \mathrm{V}$, a duration of less than $5 \mathrm{~ms}$, and a firing rate of between 2 and $20 \mathrm{~Hz}$ ". Professor Aminoff detailed the electromyography of motor unit action potential in normal muscle: The amplitude of the individual motor unit action potentials was usually between $200 \mu \mathrm{V}$ and $3 \mathrm{mV}$, the total duration of the action potentials was normally not beyond $15 \mathrm{~ms}$ depending on the muscle being examined [142].

(vii) Persistent high-frequency discharge of action potential. "Over the loudspearker, they give rise to a high-pitched repetitive click, which aids their detection". "Once present, they may persist for months or even years".

(viii) Induction (a): Disconnection of the connecting-end. "...their genesis may relate to denervated skeletal muscle fibers (i.e., the disconnection of neuromuscular junction)", "they may not appear for three to five weeks after an acute neuropathic lesion (it is because presynaptic membrane still survives in the initial stage of neuron lesion). Once present, they may persist for months or even years (it is because presynaptic membrane has been permanently deformed), until the muscle fibers have come to be reinnervated or have degenerated", "they are also seen in primary muscle diseases such as polymyositis, inclusion body myositis, and muscular dystrophy, muscle trauma, or metabolic disorders (these diseases induce deformation, degeneration, or other damage of neuromuscular junction)". "The presence of fibrillation potentials in myopathic disorders probably relates to isolation of part of the muscle fibers from their endplates, so that they are functionally denervated".

(ix) Induction (b): Hyperkalemia. “...they are also seen in hyperkalemic periodic paralysis".

(x) Summary of inductions: Both the physical action of connecting-end disconnection and the chemical action of hyperkalemia.

(xi) Termination by restoring normal connecting-end configuration, or by the degeneration of myocyte itself which loses the ability of cellular excitation. "Once present, they may persist for months or even years, until the muscle fibers have come to be reinnervated or have degenerated".

(xii) Pathophysiological significance. "They are found in denervated muscle, provided that some tissue remains viable and the muscle is warm when examined". It verifies the earlier description in the above section that "the mechanism of SSL action potential definitely sustains excitation of cell and postpones atrophy and apoptosis, thus plays the role in self-protection and self-compensation in pathophysiological significance".

In addition to the above elaboration, some other cases in this book also exhibited the features of spontaneous action potential. In the part of "Nerve Conduction Studies" edited by Daube, median neuropathies were detailed [143]:

"The most common focal mononeuropathy is the carpal tunnel syndrome, in which the median nerve is compressed in the space formed by the wrist bones and the carpal ligament". "In nerve conduction studies in carpal tunnel syndromes, severe abnormalities are associated with fibrillation potentials with a predictive accuracy of 50\%-70\% [144]". "Anterior interosseous neuropathy and pronator syndrome are usually manifested by fibrillation potentials in the appropriate muscles". "In diabetes, small vascular lesions in a multifocal distribution result in a variety of patterns of abnormality on nerve conduction studies. Among the most common patterns in diabetes are a mild, generalized distal neuropathy caused by multiple small additive lesions; and mononeuropathies of the median nerve at the wrist, ulnar nerve at the elbow, or peroneal nerve at the knee". Limb peripheral nerves surrounded by bones and ligaments, involving "median nerve at the wrist, ulnar nerve at the elbow, or peroneal nerve at the knee", are prone to being compressed to induce microcirculatory ischemia or induce disconnection due to their anatomical structures.

Amyotropic lateral sclerosis (ALS) is induced by the degeneration of motor neurons. Electromyography was characterized by the fibrillation potential as the evidence of denervation [135]. In the part of "Use of Neurophysiologic Techniques in Clinical Trials" edited by Olney, ALS was described [145]:

"Amyotropic lateral sclerosis is characterized by the progressive loss of upper and lower motor neurons. Weakness is produced primarily by the progressive degeneration of anterior horn cells in the spinal cord and neurons of the pontine and medullary motor nuclei. This lower motor neuron degeneration causes muscles to become partially denervated. The effects of acute denervation from lower motor neuron loss are partially compensated for by collateral sprouts from surviving lower motor neurons that reinnervate the denervated muscle fibers. However, at the end stage of lower motor neuron weakness, the few remaining lower motor neurons become diseased themselves, which further decrease the number of motor units per muscle as well as causing loss of compensatory reinnervation. Furthermore, compensatory reinnervation is less predominant in patients with amyotrophic lateral sclerosis who have the most rapidly progressive course. Thus, two opposing pathophysiologic mechanisms can be identified in most patients with amyotrophic lateral sclerosis throughout most of their course: (i) progressive loss of lower motor neurons; and (ii) an increase in the number of muscle fibers innervated by each surviving lower motor neurons. Although the rate at which it occurs is variable among patients, the primary process of progressive loss of lower motor neurons is universal among all patients. The amount of compensatory reinnervation also varies among patients and at different 
stages of the disease course. The utility of motor nerve conduction studies, motor unit number estimation, and quantitative EMG techniques in quantifying lower motor neuron disease in clinical trials has been reviewed [146]. These techniques are also suitable for assessing progression in other forms of lower motor neuron disease (e.g., spinal muscular atrophy)".

The above elaboration exhibits the vital pathophysicological significance of spontaneous high-frequency SSL action potential on neural regeneration.

\section{Summary}

The normal connection between cells is destroyed to cause the disconnection by stretch (e.g., AF, crush syndrome), substantial disconnection (e.g., wound), deformation or absence of the counterpart connecting-end (e.g., atrophy or degeneration), or excessive chemical actions (e.g., ACh accentuation or severe hyperkalemia). The disconnection results in spontaneous repetitive discharge, which forms spontaneous electric field. The spontaneous repetitive discharge and electric field are essentially spontaneous highfrequency action potentials. Spontaneous high-frequency action potential in vivo exhibits in tachyarrhythmias, wounds, denervation supersensitivity, neurogenic pain (hyperalgesia and allodynia), epilepsy, and diabetic pain. Spontaneous electric field generated by spontaneous high-frequency action potential is requisite for regeneration and development. SSL action potential mechanism plays the paramount role in pathophysiological significance.

To form intercellular conduction, connecting-end space exerts inwardly rectifying action on cation diffusions, which indicates the evolutionary adaptability dominates the differentiation of subcellular organelles (plasmalemma, connecting-end, and connecting-end space).

The disconnection of connecting-end space causes excessive $\mathrm{K}^{+}$outflow and secondary $\mathrm{Cl}^{-}$inflow in the connecting-end, meanwhile $\mathrm{Na}^{+}$and $\mathrm{Ca}^{2+}$ inflows are inhibited, and consequently, IPE is reduced to initiate depolarization and action potential in somatic membrane. The sustained disconnection of connecting-end space causes the sustained high-frequency SSL action potential, and the restoration of connecting-end space terminates it.

SSL action potential is comprised of connecting-end hyperpolarization and somatic membrane depolarization and action potential. Because spontaneous somatic membrane depolarization results from the reduced IPE, SSL action potential is characterized by high density, lateralized, long distance, and rapid distribution over somatic membrane with the shortened amplitude (compared with that of DD action potential), the shortened duration (i.e., highfrequency), and chaotic property.

\section{Two opposing homeostatic states of cells}

The difficulty in this chapter is to comprehend "the disconnection of connecting-end space leads to excessive $\mathrm{K}^{+}$outflow, i.e., $\mathrm{K}^{+}$leakage".

Earlier in this chapter, it has been described that the action of connecting-end space was generated by the evolutionary adaptability that connecting-end space should benefit the conduction from cell to cell. Here, three vital points are raised for the deep comprehension on the origin of connecting-end space.

\subsection{Two opposing homeostatic states of cells}

One homeostatic state (state I) is the state with a higher level of IPE (IPE $\uparrow$ ), whose consequence is the polarization of cytomembrane. The cell is landed into the resting state (non-excited state), in which only external input current can depolarize it (also called passive depolarization), the depolarization and action potential are initiated by the traditional mechanism of depolarization and action potential, i.e., DD depolarization and action potential.

The other homeostatic state (state II) is the state with a lower level of IPE (IPE $\downarrow$ ), whose consequence is the depolarization of cytomembrane (also called active depolarization), which spontaneously elicits action potential in cytomembrane. The cell is landed into the spontaneously excited state, and the depolarization and action potential are initiated by spontaneous action potential mechanism, i.e., SSL depolarization and action potential.

The relationship of IPE between state I and state II ex-

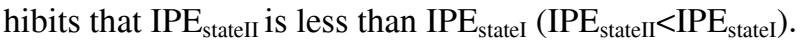

Both state I and state II land cells into the homeostasis that the states can be kept persistently and stably. The distinction of homeostasis between state I and state II exists in that state $\mathrm{I}$ is in the static homeostasis that cells are in the persistent resting state, whereas state II is in the dynamic homeostasis that cells are in the persistent spontaneously excited state. The distinctions between static homeostasis and dynamic homeostasis result in the distinct actions of state I and state II, contributing to meeting the distinct requirements that the organism demands cells.

Physiological activity excites cell from the resting state (state I). This basic resting state is requisite for cells to distinguish excitation from non-excitation, thus the basic state of cells that have a higher level of IPE is fundamentally requisite.

Some physiological or pathophysiological activities require the persistent excited state (state II) of cells, such as that as the disconnection that the cell loses the conduction from its adjacent partner occurs, the persistent spontaneous electric field formed by the persistent spontaneous high-frequency action potential is requisite for wound healing and tissue repair. 
The normal state of connecting-end space basically exerts inwardly rectifying action on cations, which leads to the higher IPE of state I (IPE stateI $>$ IPE $\left._{\text {stateII }}\right)$ with the basic resting state of the cell. The disconnection of connecting-end space abolishes inwardly rectifying action on cations, which leads to the lower IPE of state II (IPE $\left.\mathrm{stateII}_{\text {IIPE }}<\mathrm{ItateI}_{\text {s }}\right)$ that initiates spontaneous depolarization and action potential. Therefore, the key that connects the transition from state I to state II is the connecting-end space.

In summary, to land cells into the resting state, i.e., state I, a higher level of IPE is requisite. It is the aim of which the connecting-end space is formed by the evolution with an inwardly rectifying action on cations $\left(\mathrm{K}^{+}, \mathrm{Na}^{+}, \mathrm{Ca}^{2+}\right)$ which enhances $\mathrm{Na}^{+}, \mathrm{Ca}^{2+}$ inflow and inhibits $\mathrm{K}^{+}$outflow. Therefore, the primary action of connecting-end space is to land the cell into the resting state, which makes the conduction of excitation that dominates the physiological activity of cell valid (i.e., the cell can be evoked from resting state to excited state). The consequence is that the disconnection of connecting-end leads to the opposing result that inhibits $\mathrm{Na}^{+}$ and $\mathrm{Ca}^{2+}$ inflows and enhances $\mathrm{K}^{+}$outflow, which causes the reduced IPE that initiates spontaneous SSL depolarization and action potential, landing cells into spontaneously excited state.

Connecting-end space primarily exerts inwardly rectifying action on cations, and in accordance with the principle of the electrostatic field, it meanwhile exerts an inversely directed rectifying action (i.e., outwardly rectifying action) on anions (e.g., $\mathrm{Cl}^{-}$). This outwardly rectifying action on anions inhibits anion inflows (mainly $\mathrm{Cl}^{-}$inflow) in the normal state, which also contributes to the higher IPE in state I by reducing intracellular negative electropotential. The disconnection of connecting-end space abolishes this outwardly rectifying action on anions so that anion $\left(\mathrm{Cl}^{-}\right)$ inflow is enhanced, which also contributes to the lower IPE in state II by increasing intracellular negative electropotential.

\subsection{Two opposing actions in connecting-end space}

Connecting-end space basically exerts inwardly rectifying action on cations (meanwhile outwardly rectifying action on anions), which forms the resting state of cells with a basic higher level of IPE (IPE statel $\uparrow)$. The enhanced inwardly rectifying action enhances $\mathrm{Na}^{+}$and $\mathrm{Ca}^{2+}$ inflows and inhibits $\mathrm{K}^{+}$outflow, which initiates DD depolarization and action potential, with a higher level of IPE (IPE $\uparrow>$ IPE $_{\text {statel }}$ ). The weakened or abolished inwardly rectifying action inhibits $\mathrm{Na}^{+}$and $\mathrm{Ca}^{2+}$ inflows and enhances $\mathrm{K}^{+}$outflow, which lowers IPE (IPE $\downarrow<$ IPE $_{\text {statel }}$ ) and initiates spontaneous SSL depolarization and action potential.

Accordingly, connecting-end space can adjust the cell from resting state to excited state with the two opposing exciting mechanisms of DD action potential and SSL action potential. As well known, the conduction is primarily the process that evokes the cell from the resting state (non-excited state) to the excited state of action potential, thus adjusting (enhancing or weakening) inwardly rectifying action can achieve the conduction of excitation by either of the two action potential mechanisms ( $\mathrm{DD}_{\mathrm{IPE}} \uparrow / \mathrm{SSL}_{\mathrm{IPE}} \downarrow$ ). Therefore, connecting-end space is created for achieving the whole course from resting state of cells to the excitation elicited by the conduction with two opposing excitation mechanisms.

To achieve the conduction that initiates and adjusts the excitation of cells, the two opposing purposes of signals should be employed in the connecting-end space: One is exerting the signal (signal I) to enhance inwardly rectifying action on cations, which enhances $\mathrm{Na}^{+}$and $\mathrm{Ca}^{2+}$ inflows and inhibits $\mathrm{K}^{+}$outflow (meanwhile inhibits $\mathrm{Cl}^{-}$inflow), the enhanced $\mathrm{Na}^{+}$and $\mathrm{Ca}^{2+}$ inflows initiate DD depolarization and action potential; the other is exerting the signal (signal II) to weaken inwardly rectifying action on cations, which inhibits $\mathrm{Na}^{+}$and $\mathrm{Ca}^{2+}$ inflows and enhances $\mathrm{K}^{+}$outflow (meanwhile enhances $\mathrm{Cl}^{-}$inflow), and the enhanced $\mathrm{K}^{+}$outflow (meanwhile the enhanced $\mathrm{Cl}^{-}$inflow) initiates SSL depolarization and action potential. Therefore, both the two opposing actions in connecting-end space can elicit the excitation of cells, by which the aims are achieved that the chemical signals (signals I and II) of conduction initiate the excitations of cells and adjust the amplitude of excitations, with the two opposing excitation mechanisms (DD $D_{\text {IPE }} \uparrow /$ $\left.\mathrm{SSL}_{\mathrm{IPE}} \downarrow\right)$.

Hence, signal I and signal II must carry out the opposing actions to elicit the opposing excitations of cells, thus they must have the opposing chemical properties.

In myocardium that employs DD action potential mechanism in physiologic state, two signals control the excitation of cells with DD action potential mechanism: NE enhances $\mathrm{Na}^{+}$and $\mathrm{Ca}^{2+}$ inflows and inhibits $\mathrm{K}^{+}$outflow, thus enhances excitability and conduction of myocardium; by contrast, ACh plays the opposite role that inhibits $\mathrm{Na}^{+}$and $\mathrm{Ca}^{2+}$ inflows and enhances $\mathrm{K}^{+}$outflow, thus weakens excitability and conduction of myocardium. As shown earlier, excessive ACh excessively inhibits $\mathrm{Na}^{+}$inflow and $\mathrm{Ca}^{2+}$ inflow and enhances $\mathrm{K}^{+}$outflow (meanwhile enhances $\mathrm{Cl}^{-}$inflow), which induces conduction block and elicits AF with SSL action potential mechanism.

\subsection{Two opposing excitation mechanisms}

DD action potential mechanism and SSL action potential mechanism are the two opposing excitation mechanisms of cells. Which excitation mechanism the cell prefers in physiological state depends on the physiological activity of the cell. It well exhibits in the following contrast between myocardiocytes and neurons, or skeletal muscle cells.

The physiological activity of myocardium is as follows: 
(i) Myocardial contractility depends on $\mathrm{Ca}^{2+}$ inflow, which is sharply distinct from skeletal muscle that depends on $\mathrm{Ca}^{2+}$ release from sarcoplasmic reticulum (SR), which is because myocardiocytes have the poorly developed SR compared with the high-developed SR of skeletal muscle cells, so DD depolarization and action potential are preferred in which cations in connecting-end space can be inwardly driven, and the consequence is that intracellular $\mathrm{Ca}^{2+}$ concentration is capable of being increased and adjusted to adjust myocardial contractility. (ii) DD depolarization is initiated by cation inflows, in which $\mathrm{Na}^{+}$inflow determines conduction duration, and $\mathrm{Ca}^{2+}$ inflow determines myocardial contractility. (iii) It is by DD depolarization and action potential that the chemical actions of neurotransmitters (NE, ACh) can directly adjust $\mathrm{Na}^{+}$and $\mathrm{Ca}^{2+}$ inflows to adjust conduction and contractility. (iv) In addition to chemical actions, conduction duration (determined by $\mathrm{Na}^{+}$inflow) and contractility (determined by $\mathrm{Ca}^{2+}$ inflow) are also controlled by the physical actions of preload and afterload, i.e., FrankStarling's Law. It is by DD depolarization that the control of the spacing of connecting-end space by preload and afterload can directly adjust $\mathrm{Na}^{+}$and $\mathrm{Ca}^{2+}$ inflows to adjust conduction and contractility. (v) Myocardium carries out the rhythm of systole-diastole, and myocardiocytes do not need excitation-standing in physiological state.

By contrast, the physiological activities of nerve and skeletal muscle are sharply distinct from myocardium: (i) Excitation-standing state is requisite for the persistent nerve impulses (neural tone), and is requisite for the persistent contraction of skeletal muscle cells, e.g., persistent nerve impulses $\rightarrow$ persistent contraction of skeletal muscle. (ii) Skeletal muscle cells have a significantly developed SR system. Quantities of $\mathrm{Ca}^{2+}$ are released from SR to offer a high $\mathrm{Ca}^{2+}$ concentration in cytosol, and especially the persistent high $\mathrm{Ca}^{2+}$ concentration in cytosol, to support the strong and persistent myodynamia of skeletal muscle contraction. (iii) Neurons also have a high-developed endoplasmic reticulum (ER) system to offer the high $\mathrm{Ca}^{2+}$ concentration and the persistent high $\mathrm{Ca}^{2+}$ concentration state in cytosol. (iv) Skeletal muscle cells and neurons do not need the increased cation inflows because they have well developed SR/ER.

The above sharp contrast articulates that the two opposing excitation mechanisms perform the opposing functions to carry out the distinct physiological actions, either of which has the individual advantage over the other. Thus, the coexistence of two opposing excitation mechanisms is requisite for the organism. It is essentially the result of evolution that the cell in variable tissues selects the mechanism appropriate to its physiological activity from the two opposing excitation mechanisms.

\subsection{Summary}

The above descriptions focus on the two requisites of the cell in organism: The first requisite is the resting state (non-excited state), which primarily makes conduction valid and the excitation of cells can be controlled. The second requisite is the coexistence of two excitation mechanisms in organism in physiologic and pathophysiologic state, either of which has the individual special significance and is unable to take the place of the other. Both DD action potential and SSL action potential are requisite for the organism.

The key that connects resting state with the two excited states (DD action potential and SSL action potential) of the cell is connecting-end space. Connecting-end space dominates both the two requisites of cells: DD excitation (IPE $\uparrow>$ IPE) $\leftarrow$ resting state (IPE) $\rightarrow$ SSL excitation (IPE $\downarrow<$ IPE).

To recap, this section articulates not only the physiological action of connecting-end space in ion diffusions and its consequence that the disconnection leads to SSL action potential, but also the formation of two opposing conduction mechanisms, and the roles of chemical signals (the two neurotransmitters of $\mathrm{NE}$ and $\mathrm{ACh}$ ) and physical signals (the shortening/dilation of connecting-end space) played in the connecting-end space.

\section{Bioenergetic significance of spontaneous high-frequency action potential}

Spontaneous high-frequency SSL action potential generates the persistent spontaneous (i.e., endogenous) electric field firing on the closed phospholipid membrane so that myocardiocytes, neurons, skeletal muscle cells, and other cells or organelles themselves can be the sources of electricity. The spontaneous electric field generated by spontaneous high-frequency SSL action potential (depolarization-repolarization) contains both direct current electric field traveling along the membrane and alternating electric field that is perpendicular to the membrane.

Distinct from DD action potential, spontaneous high-frequency SSL action potential (e.g., disconnection-potential) is characterized by the repetitive spontaneous high-frequency discharge and electric field. Wound-induced persistent endogenous electric field had been studied since it was first detected in wounds 150 years ago [83-86,91,92]. Spinal cord damage generated persistent electrical signals [112-115]. In permanent-AF (also called longstanding AF), the electrical impulses could occur all the time for years $[28,29]$. In denervation, the spontaneous electrical signals might persist for months or even years, until the muscle fibers came to be reinnervated or had degenerated $[110,135,139]$. Endogenous electric fields had been measured during development in vertebrate embryos [117-122]. The persistent high-frequency SSL action potential of ER contributes to spontaneous $\mathrm{Ca}^{2+}$ oscillation in cells.

In summary, spontaneous high-frequency SSL action potential forms a very special and "inconceivable" phenomenon of bioelectric "perpetual motion" (the perpetual 
motion without an energy source is physically impossible) to support regeneration and development. The origination of spontaneous high-frequency SSL action potential, as described earlier, is homeostatic state II that lands cells into spontaneous excitation-standing state. The "infinite" spontaneous high-frequency discharge is the inevitable result of the closed phospholipid membrane in homeostatic state II. Spontaneous high-frequency SSL action potential first offers a template of "perpetual motion" of bioelectricity that has never been mentioned before.

As shown earlier, (i) spontaneous high-frequency SSL action potential is caused by cation leakage that can be induced by the physical actions of the dilation and disconnection of connecting-end space, or the chemical actions of ACh and hyperkalemia; and (ii) the amplitude, duration, and frequency of SSL action potential can be adjusted by the quantity of cation leakage. Thus, the further biophysical significance of spontaneous high-frequency SSL action potential exists in that it not only offers a template of electric "perpetual motion", but also offers a system how to adjust the template.

The foundation of spontaneous high-frequency SSL action potential is the closed phospholipid membrane. Utilizing renewable energy (e.g., sunlight) to supply energy (e.g., embedding photosynthetic proteins into phospholipid membrane $[147,148]$ ) for active transport can achieve perpetual discharge and electric field of spontaneous high-frequency SSL action potential in the closed phospholipid membrane. Biological perpetual electricity of spontaneous highfrequency SSL action potential may offer a novel pathway of energy source exploitation in the future.

This work is dedicated to the following professors: Young-Hoon Kim (Division of Cardiology, Cardiovascular Center, Republic of Korea), Hee Chul Han (Department of Physiology, College of Medicine, Korea University, Republic of Korea), Chang Gyu Park (Division of Cardiology, Department of Internal Medicine, Korea University Medical Center, Republic of Korea), Hyo-Soo Kim and Young Bae Park (Cardiac Catheterization Laboratory \& Coronary Intervention, National Research Laboratory for Cardiovascular Stem Cells, Department of Internal Medicine, Seoul National University Hospital, Republic of Korea), Wonchae Choe; and especially Young-Hoon Kimfor clinical cardiac electrophysiology.

This work was supported by a grant of the Korean Health Technology $R \& D$ Project, Ministry for Health, Welfare \& Family Affairs, Republic of Korea (Grant No. A 092125). The authors are grateful to Liu Xu (Department of Cardiology, Shanghai Chest Hospital Affiliated to Shanghai Jiaotong University, China), Zhang Shu and Hua Wei (Department of Cardiology, Fuwai Hospital and Cardiovascular Institute, Peking Union Medical College and Chinese Academy of Medical Sciences, Clinical EP Lab and Arrhythmia Center, China), Weon Kim (Division of Cardiology, Kyung Hee University Hospital, Republic of Korea), Chun Hwang (Utah Valley Regional Medical Center, Provo, Utah, and Krannert Heart Institute, Indiana University, USA), Peng-Sheng Chen (Krannert Institute of Cardiology and the Division of Cardiology, Department of Medicine, Indiana University School of Medicine, USA) and Jian-Fang Ren (Cardiac Electrophysiology Laboratory, University of Pennsylvania, USA) for their efforts and achievements in clinical cardiac electrophysiology.

1 Dhein S. Gap junction channels in the cardiovascular system: Phar- macological and physiological modulation. Trends Pharmacol Sci, 1998, 19: 229-241

2 van Veen A A, van Rijen H V, Opthof T. Cardiac gap junction channels: modulation of expression and channel properties. Cardiovasc Res, 2001, 51: 217-229

3 van der Velden H M, Jongsma H J. Cardiac gap junctions and connexins: Their role in atrial fibrillation and potential as therapeutic targets. Cardiovasc Res, 2002, 54: 270-279

4 Tribulová N, Knezl V, Okruhlicová L, et al. Myocardial gap junctions: Targets for novel approaches in the prevention of life-threatening cardiac arrhythmias. Physiol Res, 2008, 57: S1-S13

5 Akar F G, Nass R D, Hahn S, et al. Dynamic changes in conduction velocity and gap junction properties during development of pacing-induced heart failure. Am J Physiol Heart Circ Physiol, 2007, 293: 1223-1230

6 Poelzing S, Rosenbaum D S. Altered connexin43 expression produces arrhythmia substrate in heart failure. Am J Physiol Heart Circ Physiol, 2004, 287: 1762-1770

7 Sato T, Ohkusa T, Honjo H, et al. Altered expression of connexin43 contributes to the arrhythmogenic substrate during the development of heart failure in cardiomyopathic hamster. Am J Physiol Heart Circ Physiol, 2008, 294: 1164-1173

8 Nikolski V P, Jones S A, Lancaster M K, et al. Cx43 and dual-pathway electrophysiology of the atrioventricular node and atrioventricular nodal reentry. Circ Res, 2003, 92: 469-475

9 Zhang S W, Liu S X, Deng L B. Immunohistochemical study of Cx43 dephosphorylation in human left ventricular myocardium suffered by acute ischemia (in Chinese). Fa Yi Xue Za Zhi, 2004, 20: 136-139

10 Zhang Y, Kakinuma Y, Ando M, et al. Acetylcholine inhibits the hypoxia-induced reduction of connexin43 protein in rat myocardiocytes. PACE, 1997, 20: 1485

11 Beardslee M A, Lerner D L, Tadros P N, et al. Dephosphorylation and intracellular redistribution of ventricular connexin43 during electrical uncoupling induced by ischemia. Circ Res, 2000, 87: 656-662

12 Peters N S. New insights into myocardial arrhythmogenesis: distribution of gap-junctional coupling in normal, ischaemic and hypertrophied human hearts. Clin Sci (Lond), 1996, 90: 447-452

13 van Rijen H V, Eckardt D, Degen J, et al. Slow conduction and enhanced anisotropy increase the propensity for ventricular tachyarrhythmias in adult mice with induced deletion of connexin43. Circulation, 2004, 109: 1048-1055

14 Danik S B, Liu F, Zhang J, et al. Modulation of cardiac gap junction expression and arrhythmic susceptibility. Circ Res, 2004, 95: 10351041

15 van Rijen H V, van Veen T A, Gros D, et al. Connexins and cardiac arrhythmias. Adv Cardiol, 2006, 42: 150-160

16 Salameh A, Frenzel C, Boldt A, et al. Subchronic alpha- and beta-adrenergic regulation of cardiac gap junction protein expression. FASEB J, 2006, 20: 365-367

17 Boengler K. Stimulation of cardiac beta-adrenoceptors targets connexin 43. Br J Pharmacol, 2009, 158: 195-7

18 Sáez J C, Retamal M A, Basilio D, et al. Connexin-based gap junction hemichannels: Gating mechanisms. Biochim Biophys Acta, 2005, 1711: 215-224

19 Verselis V K, Trexler E B, Bukauskas F F. Connexin hemichannels and cell-cell channels: Comparison of properties. Braz J Med Biol Res, 2000, 33: 379-389

20 Bennett M V L, Contreras J E, Bukauskas F F, et al. New roles for astrocytes: Gap junction hemichannels have something to communicate. Trends Neurosci, 2003, 11: 610-617

21 Sáez J C, Contreras J E, Bukauskas F, et al. Gap junction hemichannels in astrocytes of the CNS. Acta Physiol Scand, 2003, 179: 9-22

22 Srinivas M, Calderon D P, Kronengold J, et al. Regulation of connexin hemichannels by monovalent cations. J Gen Physiol, 2006, 127: 67-75

23 Trexler E B, Bennett M V, Bargiello T A, et al. Voltage gating and permeation in a gap junction hemichannel. Proc Natl Acad Sci USA, 1996, 93: 5836-5841 
24 Verselis V K, Srinivas M. Divalent cations regulate connexin hemichannels by modulating intrinsic voltage-dependent gating. J Gen Physiol, 2008, 132: 315-327

25 Verselis V K, Trelles M P, Rubinos C, et al. Loop gating of connexin hemichannels involves movement of pore-lining residues in the first extracellular loop domain. J Biol Chem, 2009, 284: 4484-4493

26 Bukauskas F F, Verselis V K. Gap junction channel gating. Biochim Biophys Acta, 2004, 1662: 42-60

27 De Mello W C. Modulation of junctional permeability. Fed Proc, 1984, 43: 2692-2696

28 Zipes D P, Libby P, Bonow R O, et al. Braunwald's Heart Disease: A Text Book Of Cardiovascular Medicine. 7th ed. Philadelphia: Elsevier Saunders, 2004

29 Fuster V, Alexander R W, O'Rosurke R A, et al. Hurst's the Heart. 11th ed. New York: McGraw-Hill, 2004

30 Gourdie R G, Severs N J, Green C R, et al. The spatial distribution and relative abundance of gap-junctional connexin 40 and connexin 43 correlate to functional properties of components of the cardiac atrioventricular conduction system. Science, 1993, 105: 985-991

31 Franz M R, Burkhoff D, Yue D T, et al. Mechanically induced action potential changes and arrhythmia in isolated and in situ canine hearts. Cardiovasc Res, 1989, 23: 213-223

32 Hansen D E, Craig C S, Hondeghem L M. Stretch-induced arrhythmias in the isolated canine ventricle. Evidence for the importance of mechanoelectrical feedback. Circulation, 1990, 81: 1094-1105

33 Franz M R, Cima R, Wang D, et al. Electrophysiological effects of myocardial stretch and mechanical determinants of stretch-activated arrhythmias. Circulation, 1992, 86: 3968-3978

34 Riemer T L, Sobie E A, Tung L. Stretch-induced changes in arrhythmogenesis and excitability in experimentally based heart cell models. Am J Physiol Heart Circ Physiol, 1998, 275: 431-442

35 Ravelli F. Mechano-electric feedback and atrial fibrillation. Prog Biophys Mol Biol, 2003, 82: 137-149

36 Parker K K, Lavelle J A, Taylor L K, et al. Stretch-induced ventricular arrhythmias during acute ischemia and reperfusion. J Appl Physiol, 2004, 97: 377-383

37 Chen R L, Penny D J, Greve G, et al. Stretch-induced regional mechanoelectric dispersion and arrhythmia in the right ventricle of anesthetized lambs. Am J Physiol Heart Circ Physiol, 2004, 286: 1008-1014

38 Janse M J, Coronel R, Wilms-Schopman F J, et al. Mechanical effects on arrhythmogenesis: From pipette to patient. Prog Biophys Mol Biol, 2003, 82: 187-195

39 Ravens U. Mechano-electric feedback and arrhythmias. Prog Biophys Mol Biol, 2003, 82: 255-266

40 Xian T L, Dyachenko V, Zuzarte M, et al. The stretch-activated potassium channel TREK-1 in rat cardiac ventricular muscle. Cardiovasc Res, 2006, 69: 86-97

41 Kelly D, Mackenzie L, Hunter P, et al. Gene expression of stretch-activated channels and mechanoelectric feedback in the heart. Clin Exp Pharmacol Physiol, 2006, 33: 642-648

42 Stacy G P Jr, Jobe R L, Taylor L K, et al. Stretch-induced depolarizations as a trigger of arrhythmias in isolated canine left ventricles. Am J Physiol, 1992, 263: 613-621

43 Kohl P, Day K, Noble D. Cellular mechanisms of cardiac mechano-electric feedback in a mathematical model. Can J Cardiol, 1998, 14: $111-119$

44 Zabel M, Koller B S, Sachs F, et al. Stretch-induced voltage changes in the isolated beating heart: Importance of the timing of stretch and implications for stretch-activated ion channels. Cardiovasc Res, 1996, 32: $120-130$

45 Tan J H, Liu W, Saint D A. Differential expression of the mechanosensitive potassium channel TREK-1 in epicardial and endocardial myocytes in rat ventricle. Exp Physiol, 2004, 89: 237-242

46 Ninio D M, Saint D A. The role of stretch-activated channels in atrial fibrillation and the influence of intracellular acidosis. Prog Biophys Mol Biol, 2008, 97: 401-416

47 White E, Le Guennec J Y, Nigretto J M, et al. The effects of increasing cell length on auxotonic contractions; membrane potential and in- tracellular calcium transients in single guinea-pig ventricular myocytes. Exp Physiol, 1993, 78: 65-78

48 Kuijpers N H, ten Eikelder H M, Bovendeerd P H, et al. Mechanoelectric feedback leads to conduction slowing and block in acutely dilated atria: A modeling study of cardiac electromechanics. Am J Physiol Heart Circ Physiol, 2007, 292: 2832-2853

49 Gray R, Greve G, Chen R, et al. Right ventricular myocardial responses to chronic pulmonary regurgitation in lambs: Disturbances of activation and conduction. Pediatr Res, 2003, 54: 529-535

50 Zipes D P, Libby P, Bonow R O, et al. Braunwald's Heart Disease: A Text Book Of Cardiovascular Medicine. 7th ed. Philadelphia: Elsevier Saunders, 2004. 409

51 Fuster V, Alexander R W, O'Rosurke R A, et al. Hurst's the Heart. 11th ed. New York: McGraw-Hill, 2004. 1568

52 Gopalan S M, Flaim C, Bhatia S N, et al. Anisotropic stretch-induced hypertrophy in neonatal ventricular myocytes micropatterned on deformable elastomers. Biotechnol Bioeng, 2003, 81: 578-587

53 Allessie M A, Lammers W J E P, Smeets J R L M, et al. Experimental evaluation of Moe's multiple wavelet hypothesis of atrial fibrillation. In: Zipes D P, Jalife J, eds. Cardiac Arrhythmias. New York: Grune \& Stratton, 1985. 265-276

54 Wang Z, Page P, Nattel S. Mechanism of flecainide's antiarrhythmic action in experimental atrial fibrillation. Circ Res, 1992, 71: 271-287

55 Schauerte P, Scherlag B J, Pitha J, et al. Catheter ablation of cardiac autonomic nerves for prevention of vagal atrial fibrillation. Circulation, 2000, 102: 2774-2780

56 Oliveira M, Silva M N, Geraldes V, et al. Effects of vagal stimulation on induction and termination of atrial fibrillation in an in vivo rabbit heart model. Rev Port Cardiol, 2010, 29: 375-389

57 Oliveira M, Silva N, Geraldes V, et al. Acute vagal modulation of atrial and pulmonary veins electrophysiology increases vulnerability to atrial fibrillation. Exp Physiol, 2011, 96: 125-133

58 Liu X, Shi H F, Tan H W, et al. Decreased connexin 43 and increased fibrosis in atrial regions susceptible to complex fractionated atrial electrograms. Cardiology, 2009, 114: 22-29

59 Asmar R, O'Rourke M F, Safar M. Arterial stiffness and pulse wave velocity: Clinical applications. Paris: Elsevier, 1999. 7-8

60 Severs N J. Pathophysiology of gap junctions in heart disease. J Cardiovasc Electrophysiol, 1994, 5: 462-475

61 de Diego C, Pai R K, Chen F, et al. Electrophysiological consequences of acute regional ischemia/reperfusion in neonatal rat ventricular myocyte monolayers. Circulation, 2008, 118: 2330-2337

62 Zipes D P, Libby P, Bonow R O, et al. Braunwald's Heart Disease: A Text Book Of Cardiovascular Medicine. 7th ed. Philadelphia: Elsevier Saunders, 2004. 692

63 Nishida K, Fujiki A, Mizumaki K, et al. Canine model of Brugada syndrome using regional epicardial cooling of the right ventricular outflow tract. Cardiovasc Electrophysiol, 2004, 15: 942-944

64 Yan G X, Antzelevitch C. Cellular basis for the Brugada syndrome and other mechanisms of arrhythmogenesis associated with STsegment elevation. Circulation, 1999, 100: 1660-1666

65 Antzelevitch C, Brugada P, Brugada J, et al. The Brugada syndrome: From bench to bedside. Oxford: Blackwell Futura, 2005

66 Antzelevitch C. Brugada syndrome: Relationship with structural heart disease. Pacing Clin Electrophysiol, 2006, 29: 1130-1159

67 Papavassiliu T, Wolpert C, Flüchter S, et al. Magnetic resonance imaging findings in patients with Brugada syndrome. $\mathrm{J}$ Cardiovasc Electrophysiol, 2004, 5: 1133-1138

68 Elizari M V, Levi R, Acunzo R S, et al. Abnormal expression of cardiac neural crest cells in heart development: A different hypothesis for the etiopathogenesis of Brugada syndrome. Heart Rhythm, 2007, 4: 359-365

69 Ewart J L, Cohen M F, Meyer R A, et al. Heart and neural tube defects in transgenic mice overexpressing the $\mathrm{Cx} 43$ gap junction gene. Development, 1997, 124: 1281-1292

70 Reaume A G, de Sousa P A, Kulkarni S, et al. Cardiac malformation in neonatal mice lacking connexin43. Science, 1995, 267: 1831-1834

71 Spragg D D, Leclercq C, Loghmani M, et al. Regional alterations in protein expression in the dyssynchronous failing heart. Circulation, 
2003, 108: 929

72 Spragg D D, Akar F G, Helm R H, et al. Abnormal conduction and repolarization in late-activated myocardium of dyssynchronously contracting hearts. Cardiovasc Res, 2005, 67: 77-86

73 Zemljic-Harpf A E, Miller J C, Henderson S A, et al. Cardiacmyocyte-specific excision of the vinculin gene disrupts cellular junctions, causing sudden death or dilated cardiomyopathy. Mol Cell Biol, 2007, 27: 7522-7537

74 Kehat I, Hasin T, Aronheim A. The role of basic leucine zipper protein-mediated transcription in physiological and pathological myocardial hypertrophy. Ann N Y Acad Sci, 2006, 1080: 97-109

75 Kostetskii I, Li J, Xiong Y, et al. Induced deletion of the N-cadherin gene in the heart leads to dissolution of the intercalated disc structure. Circ Res, 2005, 96: 346-354

76 Gustafson-Wagner E A, Sinn H W, Chen Y L, et al. Loss of mXinalpha, an intercalated disk protein, results in cardiac hypertrophy and cardiomyopathy with conduction defects. Am J Physiol Heart Circ Physiol, 2007, 293: 2626-2628

77 Severs N J, Coppen S R, Dupont E, et al. Gap junction alterations in human cardiac disease. Cardiovasc Res, 2004, 62: 368-377

78 Severs N J, Dupont E, Coppen S R, et al. Remodelling of gap junctions and connexin expression in heart disease. Biochim Biophys Acta, 2004, 1662: 138-148

79 Akar F G, Spragg D D, Tunin R S, et al. Mechanisms underlying conduction slowing and arrhythmogenesis in nonischemic dilated cardiomyopathy. Circ Res, 2004, 95: 717-725

80 Nygren A, Olson M L, Chen K Y, et al. Propagation of the cardiac impulse in the diabetic rat heart: Reduced conduction reserve. $\mathrm{J}$ Physiol, 2007, 580: 543-560

81 Peters N S, Coromilas J, Severs N J, et al. Disturbed connexin43 gap junction distribution correlates with the location of reentrant circuits in the epicardial border zone of healing canine infarcts that cause ventricular tachycardia. Circulation, 1997, 95: 988-996

82 Polontchouk L, Haefliger J A, Ebelt B, et al. Effects of chronic atrial fibrillation on gap junction distribution in human and rat atria. J Am Coll Cardiol, 2001, 38: 883-891

83 DuBois-Reymond E. Vorläufiger Abriss einer Untersuchung uber den sogenannten Froschstrom und die electomotorischen Fische. Ann Phy U Chem, 1843, 58: 1-30

84 Sta Iglesia D D, Vanable J W Jr. Endogenous lateral electric fields around bovine corneal lesions are necessary for and can enhance normal rates of wound healing. Wound Repair Regen, 1998, 6: $531-542$

85 Nuccitelli R. A role for endogenous electric fields in wound healing. Curr Top Dev Biol, 2003, 58: 1-26

86 Song B, Gu Y, Pu J, et al. Application of direct current electric fields to cells and tissues in vitro and modulation of wound electric field in vivo. Nat Protoc, 2007, 2: 1479-1489

87 Chiang M C, Cragoe E J Jr, Vanable J W Jr. Intrinsic electric fields promote epithelization of wounds in the newt, Notophthalmus viridescens. Dev Biol, 1991, 146: 377-385

88 Barker A T, Jaffe L F, Vanable J W Jr. The glabrous epidermis of cavies contains a powerful battery. Am J Physiol, 1982, 242: 358366

89 Borgens R B, Vanable J W Jr, Jaffe L F. Bioelectricity and regeneration: Large currents leave the stumps of regenerating newt limbs. Proc Natl Acad Sci USA, 1977, 74: 4528-4532

90 Jaffe L F, Vanable J W Jr. Electric fields and wound healing. Clin Dermatol, 1984, 2: 34-44

91 Reid B, Song B, McCaig C D, et al. Wound healing in rat cornea: The role of electric currents. FASEB J, 2005, 19: 379-386

92 McCaig C D, Rajnicek A M, Song B, et al. Controlling cell behavior electrically: Current views and future potential. Physiol Rev, 2005, 85: 943-978

93 Hodgkin A L, Huxley A F. A quantitative description of membrane current and its application to conduction and excitation in nerve. $\mathrm{J}$ Physiol, 1952, 117: 500-544

94 Aihara K, Matsumoto G. Two stable steady states in the Hodgkin-Huxley axon. Biophys J, 1983, 41: 87-89
95 Kager H, Wadman W J, Somjen G G. Simulated seizures and spreading depression in a neuron model incorporating interstitial space and ion concentrations. J Neurophysiol, 2000, 84: 495-512

96 Junge D. Nerve and Muscle Excitation. 2nd ed. Sunderland: Sinauer Associates, 1981. 33-37

97 Mahajan A, Sato D, Shiferaw Y, et al. Modifying L-type calcium current kinetics: Consequences for cardiac excitation and arrhythmia dynamics. Biophys J, 2007, 94: 411-423

98 Omichi C, Lamp S T, Lin S F, et al. Intracellular Ca dynamics in ventricular fibrillation. Am J Physiol Heart Circ Physiol, 2004, 286: 1836-1844

99 Doi S, Nabetani S, Kumagai S. Complex nonlinear dynamics of the Hodgkin-Huxley equations induced by time scale changes. Biol Cybern, 2001, 85: 51-64

100 http://en.wikipedia.org/wiki/Chaos_theory

101 Conrad B, Sindermann F, Prochazka V J. Interval analysis of repetitive denervation potentials of human skeletal muscle. J Neurol Neurosurg Psychiatry, 1972, 35: 834-840

102 Stöhr M. Electromyographic rest-activity. Unusual forms of spontaneous discharge in healthy and sick skeletal muscle. Fortschr Med, 1977, 95: 2078-2080

103 Robinson L R. Role of neurophysiologic evaluation in diagnosis. J Am Acad Orthop Surg, 2000, 8: 190-199

104 Dumitru D, Diaz C A, King J C. Prevalence of denervation in paraspinal and foot intrinsic musculature. Am J Phys Med Rehabil, 2001, 80: 482-490

105 Vrancken A F, Franssen H, Wokke J H, et al. Chronic idiopathic axonal polyneuropathy and successful aging of the peripheral nervous system in elderly people. Arch Neurol, 2002, 59: 533-540

106 Oye C, Bouchard R, Boucher R, et al. Spontaneous activity of the putamen after chronic interruption of the dopaminergic pathway: Effect of L-dopa. J Pharmacol Exp Ther, 1970, 175: 700-708

107 Ungerstedt U, Ljungberg T, Hoffer B, et al. Dopaminergic supersensitivity in the striatum. Adv Neurol, 1975, 9: 57-65

108 Siggins G R, Hoffer B J, Bloom F E, et al. Cytochemical and electrophysiological studies of dopamine in the caudate nucleus. Res Publ Assoc Res Nerv Ment Dis, 1976, 55: 227-248

109 Schultz W, Ungerstedt U. Short-term increase and long-term reversion of striatal cell activity after degeneration of the nigrostriatal dopamine system. Exp Brain Res, 1978, 33: 159-171

110 Galarraga E, Bargas J, Martínez-Fong D, et al. Spontaneous synaptic potentials in dopamine-denervated neostriatal neurons. Neurosci Lett, 1987, 81: 351-355

111 Calabresi P, Mercuri N B, Sancesario G, et al. Electrophysiology of dopamine-denervated striatal neurons. Implications for Parkinson's disease. Brain, 1993, 116: 433-452

112 Borgens R B, Jaffe L F, Cohen M J. Large and persistent electrical currents enter the transected lamprey spinal cord. Proc Natl Acad Sci USA, 1980, 77: 1209-1213

113 Borgens R B, Roederer E, Cohen M J. Enhanced spinal cord regeneration in lamprey by applied electric fields. Science, 1981, 213: 611-617

114 Borgens R B, Blight A R, McGinnis M E. Behavioral recovery induced by applied electric fields after spinal cord hemisection in guinea pig. Science, 1987, 238: 366-369

115 Shapiro S, Borgens R, Pascuzzi R, et al. Oscillating field stimulation for complete spinal cord injury in humans: A phase 1 trial. J Neurosurg Spine, 2005, 2: 3-10

116 Daube J R. Nerve conduction studies. In: Aminoff M J, ed. Electrodiagnosis in Clinical Neurology. 5th ed. New York: Churchill Livingstone, 2005. 307

117 Jaffe L F, Stern C D. Strong electrical currents leave the primitive streak of chick embryos. Science, 1979, 206: 569-571

118 Nuccitelli R. Endogenous electric fields in embryos during development, regeneration and wound healing. Radiat Prot Dosimetry, 2003, 106: $375-383$

119 Hotary K B, Robinson K R. Endogenous electrical currents and voltage gradients in Xenopus embryos and the consequences of their disruption. Dev Biol, 1994, 166: 789-800 
120 Shi R, Borgens R B. Embryonic neuroepithelial sodium transport, the resulting physiological potential, and cranial development. Dev Biol, 1994, 165: 105-116

121 Shi R, Borgens R B. Three-dimensional gradients of voltage during development of the nervous system as invisible coordinates for the establishment of embryonic pattern. Dev Dyn, 1995, 202: 101-114

122 Levin M, Thorlin T, Robinson K R, et al. Asymmetries in $\mathrm{H}^{+} / \mathrm{K}^{+}$ATPase and cell membrane potentials comprise a very early step in left-right patterning. Cell, 2002, 111: 77-89

123 Hotary K B, Robinson K R. Evidence of a role for endogenous electrical fields in chick embryo development. Development, 1992, 114: 985-996

124 Hinkle L, McCaig C D, Robinson K R. The direction of growth of differentiating neurones and myoblasts from frog embryos in an applied electric field. J Physiol, 1981, 314: 121-135

125 Erickson C A, Nuccitelli R. Embryonic fibroblast motility and orientation can be influenced by physiological electric fields. J Cell Biol, 1984, 98: 296-307

126 Mycielska M E, Djamgoz M B. Cellular mechanisms of direct-current electric field effects: Galvanotaxis and metastatic disease. J Cell Sci, 2004, 117: 1631-1639

127 McCaig C D, Zhao M. Physiological electrical fields modify cell behaviour. Bioessays, 1997, 19: 819-826

128 McCaig C D, Rajnicek A M, Song B, et al. Has electrical growth cone guidance found its potential? Trends Neurosci, 2002, 25: 354359

129 Nishimura K Y, Isseroff R R, Nuccitelli R. Human keratinocytes migrate to the negative pole in direct current electric fields comparable to those measured in mammalian wounds. J Cell Sci, 1996, 109: 1199-1207

130 Pullar C E, Baier B S, Kariya Y, et al. B 4 integrin and EGF coordinately regulate electric field mediated directional migration via Rac1. Mol Biol Cell, 2006, 17: 4925-4935

131 Song B, Zhao M, Forrester J V, et al. Electrical cues regulate the orientation and frequency of cell division and the rate of wound healing in vivo. Proc Natl Acad Sci USA, 2002, 99: 13577-13582

132 Zhao M, Forrester J V, McCaig C D. A small, physiological electric field orients cell division. Proc Natl Acad Sci USA, 1999, 96: 4942-4946

133 Ratkay-Traub I, Hopp B, Bor Z, et al. Regeneration of rabbit cornea following excimer laser photorefractive keratectomy: A study on gap junctions, epithelial junctions and epidermal growth factor receptor expression in correlation with cell proliferation. Exp Eye Res, 2001, 73: 291-302

134 Aminoff M J, ed. Electrodiagnosis in Clinical Neurology. 5th ed. New York: Churchill Livingstone, 2005

135 Aminoff M J. Clinical electromyography. In: Aminoff M J, ed. Electrodiagnosis in Clinical Neurology. 5th ed. New York: Churchill Livingstone, 2005. 238-239

136 Purves D, Sakmann B. Membrane properties underlying spontaneous activity of denervated muscle fibres. J Physiol, 1974, 239: 125

137 Thesleff S, Ward M R. Studies on the mechanism of fibrillation potentials in denervated muscle. J Physiol, 1975, 244: 313

138 Smith J W, Thesleff S. Spontaneous activity in denervated mouse diaphragm muscle. J Physiol, 1976, 257: 171

139 Kraft G H. Decay of fibrillation potential amplitude following nerve injury. Electroencephalogr Clin Neurophysiol, 1985, 60: 105

140 Partanen J V, Danner R. Fibrillation potentials after muscle injury in humans. Muscle Nerve, 1982, 5: S70

141 Desmedt J E. Muscular dystrophy contrasted with denervation: Different mechanisms underlying spontaneous fibrillations. Electroencephalogr Clin Neurophysiol Suppl, 1978, 34: 531

142 Aminoff M J. Clinical electromyography. In: Aminoff M J, ed. Electrodiagnosis in Clinical Neurology. 5th ed. New York: Churchill Livingstone, 2005. 236-237

143 Daube J R. Nerve conduction studies. In: Aminoff M J, ed. Electrodiagnosis in Clinical Neurology. 5th ed. New York: Churchill Livingstone, 2005. 306-309

144 Werner R A, Albers J W. Relation between needle electromyography and nerve conduction studies in patients with carpal tunnel syndrome. Arch Phys Med Rehabil, 1995, 76: 246

145 Olney R K. Use of neurophysiologic technique in clinical trials. In: Aminoff M J, ed. Electrodiagnosis in Clinical Neurology. 5th ed. New York: Churchill Livingstone, 2005. 787-788

146 Bromberg M B. Electrodiagnostic studies in clinical trials for motor neuron disease. J Clin Neurophysiol, 1998, 15: 117

147 Tavano C L, Donohue T J. Development of the bacterial photosynthetic apparatus. Curr Opin Microbiol, 2006, 9: 625-631

148 Mullineaux C W. The thylakoid membranes of cyanobacteria: Structure, dynamics and function. Aust J Plant Physiol, 1999, 26: 671-677

Open Access This article is distributed under the terms of the Creative Commons Attribution License which permits any use, distribution, and reproduction in any medium, provided the original author(s) and source are credited. 